NBER WORKING PAPER SERIES

\title{
MONETARY POLICY AND THE PREDICTABILITY OF NOMINAL EXCHANGE RATES
}

\author{
Martin Eichenbaum \\ Benjamin K. Johannsen \\ Sergio Rebelo \\ Working Paper 23158 \\ http://www.nber.org/papers/w23158 \\ NATIONAL BUREAU OF ECONOMIC RESEARCH \\ 1050 Massachusetts Avenue \\ Cambridge, MA 02138 \\ February 2017
}

The views expressed here are those of the authors and do not necessarily reflect the view of the Board of Governors, the FOMC, anyone else associated with the Federal Reserve System, or the National Bureau of Economic Research. We thank Adrien Auclert, Luigi Bocola, Ariel Burstein, Giancarlo Corsetti, Geoffrey Dunbar, Charles Engel, Gaetano Gaballo, Zvi Hercovitz, Ida Hjorts $\varnothing$, Oleg Itskhoki, Dmitry Mukhin, Paulo Rodrigues, Christopher Sims, and Oreste Tristani for their comments and Martin Bodenstein for helpful discussions.

At least one co-author has disclosed a financial relationship of potential relevance for this research. Further information is available online at http://www.nber.org/papers/w23158.ack

NBER working papers are circulated for discussion and comment purposes. They have not been peer-reviewed or been subject to the review by the NBER Board of Directors that accompanies official NBER publications.

(C) 2017 by Martin Eichenbaum, Benjamin K. Johannsen, and Sergio Rebelo. All rights reserved. Short sections of text, not to exceed two paragraphs, may be quoted without explicit permission provided that full credit, including $(\odot$ notice, is given to the source. 
Monetary Policy and the Predictability of Nominal Exchange Rates

Martin Eichenbaum, Benjamin K. Johannsen, and Sergio Rebelo

NBER Working Paper No. 23158

February 2017

JEL No. E52,F31,F41

\section{ABSTRACT}

This paper studies how the monetary policy regime affects the relative importance of nominal exchange rates and inflation rates in shaping the response of real exchange rates to shocks. We document two facts about inflation-targeting countries. First, the current real exchange rate predicts future changes in the nominal exchange rate. Second, the real exchange rate is a poor predictor of future inflation rates. We estimate a medium-size DSGE open-economy model that accounts quantitatively for these facts as well as other empirical properties of real and nominal exchange rates. The key estimated shocks that accounts for the dynamics of exchange rates and their covariance with inflation are disturbances to the foreign demand for dollar-denominated bonds.

Martin Eichenbaum

Department of Economics

Northwestern University

2003 Sheridan Road

Evanston, IL 60208

and NBER

eich@northwestern.edu

Benjamin K. Johannsen

Board of Governors of the Federal Reserve System

20th and C Streets, N.W.

Washington, DC 20551

benjamin.k.johannsen@frb.gov
Sergio Rebelo

Northwestern University

Kellogg School of Management

Department of Finance

Leverone Hall

Evanston, IL 60208-2001

and CEPR

and also NBER

s-rebelo@northwestern.edu 


\section{Introduction}

This paper studies how monetary policy affects the relative importance of nominal exchange rates $(N E R \mathrm{~s})$ and inflation rates in shaping the response of real exchange rates $(R E R \mathrm{~s})$ to shocks.

Our analysis has four components. First, we document key empirical regularities that govern the relation between the current $R E R$ and future values of inflation and the $N E R$. We then show that these regularities depend critically on the monetary policy regime in effect. Second, we provide a simple theory that explains these regularities. Third, we identify the key shocks that have driven the U.S. RER, NER and their relation to inflation under an inflation-targeting regime. We do so using an estimated three-country DSGE model of the World economy. Finally, we show how the adjustment to these shocks would have occurred under alternative monetary policy regimes.

Building on a long empirical literature discussed below, we document two facts about $R E R s$ and NERs for a set of inflation-targeting, benchmark countries. To describe our results, it is useful to define the $R E R$ as the price of the foreign-consumption basket in units of the home-consumption basket and the NER as the price of the foreign currency in units of the home currency. Our first fact is that the current $R E R$ is highly negatively correlated with future changes in the $N E R$ at horizons greater than two years. This correlation is stronger the longer is the horizon. Our second fact is that the $R E R$ is virtually uncorrelated with future inflation rates at all horizons. Taken together, these facts imply that the $R E R$ adjusts to shocks in the medium and long run overwhelmingly through changes in the NER, not through differential inflation rates.

Critically, these facts depend on the monetary policy regime in effect. To show this dependency, we re-do our analysis for China which is on a quasi-fixed exchange rate regime versus the U.S. dollar; for Hong Kong which has a fixed exchange rate versus the U.S. dollar; and for the euro-area countries, which have fixed exchange rates with each other. In all of these cases, the current $R E R$ is highly negatively correlated with future relative inflation rates. In contrast to our benchmark countries, the $R E R$ adjusts overwhelmingly through predictable inflation differentials.

We also redo our analysis for a set of countries that adopted inflation targeting after our benchmark countries (around the year 2000). This set of countries consists of Brazil, Chile, Colombia, Indonesia, Israel, Mexico, South Korea, and Thailand. We show that when these countries adopted 
floating exchange rates and inflation targeting, the dynamic co-movements of the $N E R$, the $R E R$, and inflation became qualitatively and quantitatively similar to those in our benchmark countries. This type of sensitivity to the monetary policy regime is precisely what we would expect given the Lucas (1976) critique.

A natural question is whether our findings are spurious in the sense that they might primarily reflect small sample sizes and persistent $R E R \mathrm{~s} .{ }^{1}$ To address these concerns, we show that outof-sample forecasts of the $N E R$ based on the $R E R$ beat a random-walk forecast at medium and long horizons. We argue that this finding is extremely unlikely if the $N E R$ is not predictable, regardless of whether the $R E R$ is stationary or not. This result strongly supports the view that our empirical findings are not spurious.

Having established our key facts, we turn to the underlying economics. We begin with a simple two-country endowment model to highlight the core qualitative explanation of our results for the benchmark countries. This explanation relies on two key assumptions: the monetary authority follows an inflation-targeting policy like a Taylor rule and there is home bias in consumption.

The intuition for why these two assumptions generate the relevant empirical regularities is as follows. Consider a persistent fall in the domestic endowment. This shock leads to a rise in the price of the domestic good. Consumers combine a domestic and foreign good into a final consumption good. Because of home bias, the domestic good has a higher weight than the foreign good in the domestic consumer basket. So, after the shock, the price of the foreign consumption basket in units of the home consumption basket falls, i.e. the $R E R$ falls. Since the home and foreign monetary authorities follow a Taylor rule that keeps inflation relatively stable, the $R E R$ must adjust through movements in the NER. This result holds, even though prices are perfectly flexible in our simple model.

We next turn to the question: what shocks and frictions account quantitatively for the movements in the $R E R$ and the $N E R$ as well as their covariance with inflation? To answer this question, we construct and estimate a medium-scale three-country (U.S., Germany, and the rest of the World) DSGE model. Consistent with our simple model, we assume that all three countries follow

\footnotetext{
${ }^{1}$ Similar concerns lie at the heart of ongoing debates about the predictability of the equity premium based on variables like the price-dividend ratio (see Stambaugh (1999), Boudoukh, Richardson and Whitelaw (2006), and Cochrane (2008)).
} 
a Taylor rule and have home bias in consumption. Production requires labor and capital services. Nominal prices and wages are set subject to Calvo-style frictions. There is local currency pricing and assets are incomplete: the only internationally trade asset is a dollar-denominated bond. ${ }^{2}$ We allow for many different types of shocks to affect economic agents and economic activity. In this way we can estimate which shocks are important in practice.

According to our estimated model, the key shock that drives the correlation between the current $R E R$ and future changes in the NER are shocks to the foreign demand for dollar-denominated bonds. In particular, over two-thirds of the relevant covariances are driven by this shock. The same shock accounts for over 70 percent of the unconditional variance of the $R E R$ at business-cycle frequencies. Significantly, this shock is not an important driver of either U.S. or German output fluctuations at business-cycle frequencies.

These results are interesting to the extent that our model is a credible representation of the data. Our estimated model has a number quantitative of properties that lend support to its credibility. First, it accounts quantitatively for the correlations between the current $R E R$, future inflation rates and changes in the $N E R$. Second, it accounts quantitatively for the volatility of the $R E R$ and changes in the $N E R$, the persistence of the $R E R$ and the high correlation between the $R E R$ and the $N E R$. Third, it accounts quantitatively for the failure of uncovered interest parity (UIP) as measured by the estimated slope coefficient in a regression of the change in the $N E R$ on the interest-rate differential (see Fama (1984)). The model is also consistent with Backus and Smith (1993)'s finding of a disconnect between relative consumption and the $R E R$, a fact that is inconsistent with a wide class of models.

Finally, we use our estimated model to ask the counterfactual question: given the estimated distribution of the shocks that occurred in our sample period, how would the economy have reacted under alternative monetary-policy regimes? To this end, we consider an exchange-rate-targeting regime as well as a regime with capital controls. The latter are modeled as a large cost of holding foreign bonds. Under an exchange-rate-targeting regime, the $N E R$ plays a substantially smaller role and differential inflation a larger role in re-establishing long-run PPP. Additionally, the $R E R$ is

\footnotetext{
${ }^{2}$ Maggiori et al. (2018) document that almost all bonds that are internationally traded are denominated in U.S. dollars.
} 
more persistent than under nominal exchange rate targeting. In contrast, modest capital controls, as we model them, have little impact on the equilibrium of the economy.

Our paper is organized as follows. Section 2 briefly discusses how our paper relates to the

literature. Section 3 contains our empirical results. Section 4 offers intuition for the drivers of our empirical results using a simple model. In Section 5, we build a medium-scale DSGE that we estimate with full-information Bayesian methods. In Section 6, we show that the estimated medium-scale DSGE model can explain our correlation estimates reported in Section 3. We discuss which estimated shocks explain those correlations and the movements in the $R E R$. In addition we explore how the $R E R$ would have adjusted to shocks under alternative monetary policy regimes. Section 7 concludes.

\section{Relation to the literature}

Our work is related to fourth strands of the literature. The first strand studies the medium- and long-run predictability of $N E R$ s. For example, Mark (1995) and Engel et al. (2007) find evidence of predictability at medium and long horizons. See Rossi (2013) for a recent survey. There is a closely associated body of work demonstrating that relative purchasing power parity (PPP) holds in the long run so that RERs are mean reverting and therefore predictable (see Rogoff (1996) and Taylor and Taylor (2004) for a review). In general, the predictability of the $R E R$ or the fact that relative PPP holds in the long run, does not imply that the $N E R$ is predictable. For example, if monetary policy seeks to limit the volatility of the $N E R$, the $R E R$ converges to its unconditional mean primarily via inflation differentials rather than sustained, predictable movements in the $N E R$.

Our contribution to this literature is to draw a tight connection between the usefulness of the current $R E R$ in predicting the future $N E R$ (in and out of sample) and the monetary-policy regime in effect. We also document that our predictability results are robust to the possibility that the $R E R$ is not stationary. Finally, we construct and estimate a medium-scale, open-economy DSGE model which is quantitatively consistent with the dynamic correlations that drive the predictability of the $N E R$ in inflation-targeting regimes.

Our empirical predictability results pertain to medium- and long-run horizons and are dis- 
tinct from the voluminous literature started by Meese and Rogoff (1983) on the out-of-sample predictability of the NER at short horizons (up to one year). Our predictability results are also distinct from Mussa (1986)'s famous demonstration that contemporaneous changes in the $N E R$ and the $R E R$ are highly correlated.

The second relevant strand of the literature discusses the importance of the monetary regime for the behavior of the RER. See, for example, Mussa (1986), Baxter and Stockman (1989), Henderson and McKibbin (1993), Sarno and Valente (2006), Engel et al. (2007), and Engel (2018). Our contribution is to focus on the behavior of the $R E R$ under an inflation targeting regime per se and to use our estimated DSGE model to study how the $N E R$, the $R E R$, and the real economy would have evolved under alternative monetary regimes.

The third relevant strand of the literature studies a myriad of failures of standard open-economy macro models, including the failure of UIP, the disconnect between the $R E R$ and relative consumption across countries. In contemporaneous work, Itskhoki and Mukhin (2017) argue that financial shocks, like shocks to the global demand for dollar-denominated bonds, can explain these and other failures. Jiang et al. (2018) also stress the importance of these types of shocks as drivers of U.S. NERs. Our contribution relative to this literature is to formally estimate which shocks are the key drivers of the $R E R$ and the $N E R$ under an inflation-targeting regime. Because we formally estimate our model, we can use it to investigate how exchange rates and inflation would have behaved given the same shock distribution as in our sample period but under alternative monetary policy regimes.

The fourth strand of related literature pertains to estimated open-economy DSGE models. Lubik and Schorfheide (2006) estimated a small-scale two-country DSGE model with Bayesian methods for the U.S. and the euro area. These authors focus on the challenges to estimation, including model specification and identification problems. Kollmann et al. (2016) estimate a largescale three-region model for the U.S., the euro area, and the rest of the World. Those authors focus on the post-crisis divergence in real output growth between the U.S. and the euro area. We estimate a medium-scale, three-region DSGE model and focus on identifying which shocks are the important drivers of $R E R \mathrm{~s}$ and $N E R \mathrm{~s}$. 


\section{Some empirical properties of exchange rates}

In this section, we present our empirical results regarding $N E R \mathrm{~s}, R E R \mathrm{~s}$, and relative inflation rates. We use consumer price indexes for all items and average quarterly $N E R$ s versus the U.S. dollar. ${ }^{3}$

\subsection{Data}

We initially focus on a benchmark group of advanced economies - Australia, Canada, Germany, New Zealand, Sweden, and the UK. Ilzetzki et al. (2017a,b) characterize these countries, except for Germany, as having adopted inflation targeting before 1997. We limit the set of countries to those that adopted inflation targeting before 1997 because we need to have sufficient data to perform our statistical analyses.

Ilzetzki et al. (2017a,b) characterize Germany as following a freely-floating exchange regime in the post Bretton Woods era. However, Bernanke and Mihov (1997) argue that, even though Germany never explicitly adopted an inflation-targeting regime, the Bundesbank was in fact targeting inflation. For this reason, we include Germany in our benchmark group. ${ }^{4}$ For Germany, we start the sample period in 1982:Q4, which is the beginning of the period for which, according to Clarida et al. (1998), U.S. monetary policy is best characterized as a stable Taylor rule. ${ }^{5}$

We exclude from our benchmark sample period data from 2008:Q4 to the present because shortterm U.S. nominal interest rates were at or near their effective lower bound. ${ }^{6}$ Table 16 summarizes the start and end dates of the sample period for our benchmark countries. Appendix A reports results obtained starting the sample period in 1973 and extending the sample period after 2008.

We compare results for the benchmark inflation targeters with those for China (from 1994 through 2008), which has been on a quasi-fixed exchange rate vis-à-vis the U.S. dollar, and for Hong Kong (from 1982 through 2008), which has a fixed exchange rate vis-à-vis the U.S. dollar.

\footnotetext{
${ }^{3}$ For bilateral exchange rate data between the U.S. and other countries, as well as for consumer price indexes, we use data from from the International Monetary Fund's International Financial Statistics database.

${ }^{4}$ As in Engel et al. (2007), we merge exchange rate data for the German Mark and the euro post 1999.

${ }^{5}$ The beginning of the sample period for Australia, Canada, Germany, New Zealand, Sweden, and the U.K. is 1993:Q3, 1991:Q2, 1982:Q4, 1990:Q1, 1996:Q1, 1992:Q4, respectively.

${ }^{6}$ See Amador et al. (2017) for a discussion of the effect of the zero lower bound on exchange-rate policies.
} 
We also analyze data starting in 1999 for France, Ireland, Italy, Portugal, and Spain where the $R E R$ and relative inflation rates are defined relative to Germany.

In addition, we report results for a subset of our statistical analyses for counties that Ilzetzki et al. (2017a,b) characterize as becoming inflation targeters between 1997 and 2002. This set of countries consists of Brazil, Chile, Colombia, Israel, Mexico, Norway, Peru, Philippines, South Africa, South Korea, and Thailand. ${ }^{7}$ We refer to this set of countries as the recent inflation targeters. We summarize the dates at which the benchmark countries and the recent inflationtargeting countries adopted the inflation-targeting framework in Appendix A.

\subsection{Results for inflation-targeting countries}

We define the $R E R$ for country $i$ relative to the U.S. as

$$
R E R_{i, t}=\frac{N E R_{i, t} P_{i, t}}{P_{t}}
$$

where $N E R_{i, t}$ is the price of the foreign currency (U.S. dollars per foreign currency unit). The variables $P_{t}$ and $P_{i, t}$ denote the consumer price index in the U.S. and in country $i$, respectively. We assume that the $R E R$ is stationary and offer supporting evidence later in this section. ${ }^{8}$ Given this assumption, the $R E R$ must adjust back to its mean after a shock via changes in the $N E R$ or changes in relative prices.

Figure 1 displays scatter plots of the $\log \left(R E R_{i, t}\right)$ against $\log \left(N E R_{i, t+h} / N E R_{i, t}\right)$ at different horizons, $h$, for our benchmark countries. Two properties of this figure are worth noting. First, consistent with the notion that exchange rates behave like random walks at high frequencies, there is no obvious relationship between the $\log \left(R E R_{i, t}\right)$ and $\log \left(N E R_{i, t+h} / N E R_{i, t}\right)$ at a one-year horizon. However, as the horizon expands, the correlation between $\log \left(R E R_{i, t}\right)$ and $\log \left(N E R_{i, t+h} / N E R_{i, t}\right)$ rises. The negative relation is very pronounced at the 5 -year horizon.

\footnotetext{
${ }^{7}$ Some countries included in Ilzetzki et al. (2017a,b) are excluded from our analysis because their data is available only for short samples.

${ }^{8}$ See Rogoff (1996) for an early discussion of the stationarity of the $R E R$.
} 


\subsubsection{Nominal exchange rate regressions}

We now discuss results for the benchmark countries based on the following $N E R$ regression

$$
\log \left(\frac{N E R_{i, t+h}}{N E R_{i, t}}\right)=\alpha_{i, h}^{N E R}+\beta_{i, h}^{N E R} \log \left(R E R_{i, t}\right)+\varepsilon_{i, t, t+h}^{N E R}
$$

for country $i$ at horizon $h=1,2, \ldots, H$ years. Panel (a) of Table 1 reports estimates of $\beta_{i, h}^{N E R}$, along with standard errors, for the benchmark inflation-targeting countries. ${ }^{9}$ A number of features are worth noting. First, the estimated values of $\beta_{i, h}^{N E R}$ are negative for all $h$. Second, the estimated values of $\beta_{i, h}^{N E R}$ for all $i$ are statistically significant at three-year horizons or longer. Third, in general, the estimated value of $\beta_{i, h}^{N E R}$ increases in absolute value for roughly the first five years and then stabilizes.

Taken together, the results in Table 1 strongly support the conclusion that, for our benchmark countries, the current $R E R$ is highly negatively correlated with changes in future $N E R$ s at horizons of three or more years. These results are consistent with those obtained by Cheung et al. (2004) using a vector error-correction model. One substantive difference between our results and theirs is that, for horizons greater than one year, our point estimates of $\beta_{i, h}^{N E R}$ are greater than one, indicating that the $N E R$ adjusts more than the $R E R$ over time. This finding reflects the fact relative inflation rates initially move in the wrong direction for re-establishing long-run relative PPP.

\subsubsection{Relative price regressions}

We now consider results based on the following relative-price regression

$$
\log \left(\frac{P_{i, t+h} / P_{t+h}}{P_{i, t} / P_{t}}\right)=\alpha_{i, h}^{\pi}+\beta_{i, h}^{\pi} \log \left(R E R_{i, t}\right)+\varepsilon_{i, t, t+h}^{\pi}
$$

This regression quantifies how much of the adjustment in the $R E R$ occurs via changes in relative rates of inflation across countries. Panel (a) of Table 2 reports our estimates and standard errors for

\footnotetext{
${ }^{9}$ We compute standard errors using an estimator of Newey and West (1987) with the number of lags equal to the forecasting horizon plus eight quarters. If not feasible, we use the sample size minus two quarters.
} 
the slope coefficients $\beta_{i, h}^{\pi}$. The key result is that the coefficients are small relative to the estimated values of $\beta_{i, h}^{N E R}$. Moreover, the estimated values of $\beta_{h}^{\pi}$ and $\beta_{i, h}^{\pi}$ are not statistically different from zero. Taken together, these results suggest that movements in relative prices account for a small fraction of movements in $R E R \mathrm{~s}$.

\subsection{Sensitivity to monetary policy}

Our basic hypothesis is that the process by which the $R E R$ adjusts to shocks depends critically on the monetary-policy regime. We provide two types of evidence in favor of this hypothesis. First, we redo our analysis for countries that are on fixed or quasi-fixed exchange regimes. Second, we consider a number of countries that adopted inflation targeting relatively recently. We study the behavior of $R E R$ 's, $N E R$ 's, and relative inflation rates before and after countries adopt inflation targeting.

\subsubsection{Fixed and quasi-fixed exchange rates}

In this subsection, we redo our analysis for countries with fixed or quasi-fixed exchange rates. Results for China and Hong Kong, which have quasi-fixed and fixed exchange rates, respectively, are reported in panel (b) of Table 1 and panel (b) of Table 2. Several features of these results are worth noting. First, the estimated values of $\beta_{i, h}^{N E R}$ are small relative to the estimates for our benchmark countries. Second, the estimated values of $\beta_{i, h}^{\pi}$ are statistically significant at every horizon and are large relative to the estimates for our benchmark countries. Third, the estimated value of $\beta_{i, h}^{\pi}$ are larger at longer horizons, $h$.

We also consider several euro area countries - France, Ireland, Italy, Portugal, and Spain — visà-vis Germany, starting in 1999. For these countries, the $N E R$ is fixed. Results for regression (3) are reported in panel (c) of Table 2. As was the case for China and Hong Kong vis-à-vis the United States, the estimated values of $\beta_{i, h}^{\pi}$ are large, rise in magnitude with the horizon, and are statistically significant at long horizons.

In sum, for economies with fixed or quasi-fixed exchange rates, the $R E R$ adjusts overwhelmingly through predictable inflation differentials, not through changes in the $N E R$. 


\subsubsection{Countries with changes in exchange rate policy}

In this subsection, we redo our analysis for recent inflation-targeting countries (Brazil, Chile, Colombia, Israel, Mexico, Norway, Peru, Philippines, South Africa, South Korea and Thailand). We consider two sample periods. The first sample goes from 1982:Q4 until the date at which the country adopted inflation targeting. The second sample begins when the country adopted inflation targeting and ends in 2018:Q4. We include the period in which the zero lower bound (ZLB) is binding in the U.S. and in some other countries in order to have enough observations to estimate our regressions at a five-year horizon. Our experience with the benchmark countries suggests that including the ZLB period has a mild effect on the coefficients in regressions (2) and (3) (see Appendix A).

Tables (3) and (4) report our estimates of $\beta_{i, h}^{N E R}$ and $\beta_{i, h}^{\pi}$, using data from the first sample. In contrast to our benchmark results, the estimates of $\beta_{i, h}^{N E R}$ and $\beta_{i, h}^{\pi}$ do not follow the consistent pattern observed for the benchmark flexible exchange rate countries. Indeed, there is no apparent pattern across the countries considered.

Tables (3) and (4) also report results for the second sample in which all of the countries have adopted inflation targeting. In sharp contrast to the first-sample results, now for every country

the estimates of $\beta_{i, h}^{N E R}$ are negative and statistically different from zero at longer horizons. For almost all the countries the absolute value of the coefficients grows with the size of $h$. By contrast, the estimates of $\beta_{i, h}^{\pi}$ are relatively small in the inflation-targeting sample.

In sum, once we control for the monetary regime, the co-movement between $N E R \mathrm{~s}$, inflation and RERs is very similar in the recent inflation-targeting countries and the benchmark countries. We view these results as supportive of our hypothesis that the monetary-policy regime is a central determinant of the way that the $R E R$ adjusts to shocks.

\subsection{Out-of-sample forecasts}

In the previous section, we argue that for our inflation targeting countries, changes in the $N E R$ at long horizons display a strong negative correlation with the current level of the $R E R$. A potential problem with this result is that if the $R E R$ is very persistent, we might find in-sample 
predictability when none is actually present. Here, we focus on the usefulness of the $R E R$ in outof-sample forecasting to test the null hypothesis that the $N E R$ is not predictable. Our key result is that if we control for the monetary-policy regime in effect, we can reject this null hypothesis. We show that using information about the $R E R$ systematically helps forecast the $N E R$ out-of-sample, at medium and long-run horizons. If we don't control for the monetary policy regime in effect, then it is difficult to reject the hypothesis that the $N E R$ is not predictable.

Our forecasting equation for the $N E R$ is

$$
\log \left(\frac{N E R_{i, t+h}}{N E R_{i, t}}\right)=\beta_{h}^{N E R}\left(\log \left(R E R_{i, t}\right)-\mu_{R E R, i}\right)+\varepsilon_{i, t, t+h}^{N E R} .
$$

Notice that the parameter $\beta_{h}^{N E R}$ is common across countries. This specification corresponds to an unbalanced panel with a common slope coefficient. ${ }^{10}$ The value $\mu_{R E R, i}$ is the mean of $\log \left(R E R_{i, t}\right)$, calculated using data from the date a country adopts inflation targeting up to date $t$. Our forecasting equation is exact in a model where symmetric countries follow the same monetary policy in the sense that they would have a common value of $\beta_{h}^{N E R}$ and the expected steady-state change in the nominal exchange rate is zero. Because we need to have an initial estimate for $\mu_{R E R, i}$, we require that a country be in the sample for at least three years before we include it in the regression analysis. We do not start out-of-sample forecasting until 1993, at which point Germany and New Zealand are in in the sample. ${ }^{11}$

We assess our ability to forecast the $N E R$ relative to a forecast of no change. The latter is the benchmark in the literature and corresponds to the assumption that the $N E R$ is a random walk without drift. Define the RMSPE for country $i$ associated with forecasts based on equation (4) as

$$
\sigma_{i, B, h}=\left\{\frac{1}{T_{i, h}} \sum_{t=0}^{T_{i, h}}\left[f_{i, t, t+h}-\log \left(\frac{N E R_{i, t+h}}{N E R_{i, t}}\right)\right]^{2}\right\}^{1 / 2} .
$$

Here, $T_{i, h}$ denotes the number of forecasts for $\log \left(N E R_{i, t+h} / N E R_{i, t}\right)$ in our sample, and $f_{i, t, t+h}$

\footnotetext{
${ }^{10}$ In adopting this approach, we follow Mark and Sul (2001), Groen (2005), Engel et al. (2007), and Mark and $\mathrm{Sul}$ (2011) who use panel methods to improve the forecasting power of exchange-rate models.

${ }^{11}$ In practice, quarterly consumer price indexes are available with a one-period lag. To address this potential source of look-ahead bias, we re-did all of our analysis with a measure the $R E R$ for country $i$ using lagged price indexes. We found that our results are very robust to this change.
} 
is the forecast of $\log \left(N E R_{i, t+h} / N E R_{i, t}\right)$ based on equation (4). We denote by $\sigma_{i, R W, h}$ the corresponding RMSPE associated with the no-change forecast from a random-walk model.

For each country $i$, we report the ratio of the RMSPE associated with the benchmark and random walk specifications, $\sigma_{i, B, h} / \sigma_{i, R W, h}$. We also compute a pooled RMSPE implied by our forecasting equation for all of the countries in our sample, defined as

$$
\sigma_{B, h}=\left\{\frac{1}{\sum_{i} T_{i, h}} \sum_{i} \sum_{t=0}^{T_{i, h}}\left[f_{i, t, t+h}-\log \left(\frac{N E R_{i, t+h}}{N E R_{i, t}}\right)\right]^{2}\right\}^{1 / 2}
$$

We denote by $\sigma_{R W, h}$ the pooled RMSPE implied by the random-walk forecast and report the ratio of the pooled RMSPEs, $\sigma_{B, h} / \sigma_{R W, h}$.

We initially limit the analysis to our benchmark countries. Panel (a) of Table (5) reports relative RMSPEs for each country and for the pooled sample. For the pooled results, forecasts based on equation (4) outperform the random-walk model at all horizons greater than two years. Remarkably, at the four- and six-year horizons, forecasting equation (4) outperforms the random walk by 24 percent and 50 percent, respectively. ${ }^{12}$

We now test the hypothesis that the relative RMSPEs reported in panel (a) of Table 5 were generated by a DGP in which the $N E R$ is a random walk. Under this hypothesis, changes in the NER should not be predictable. We test this hypothesis using a bootstrap procedure. ${ }^{13}$ We assume that the stochastic processes for $N E R_{i, t}$ and $R E R_{i, t}$ are given by

$$
\begin{aligned}
\log \left(\frac{N E R_{i, t}}{N E R_{i, t-1}}\right) & =\varepsilon_{i, t}^{N E R}, \\
A_{i}(L)\left(\log \left(R E R_{i, t}\right)-\mu_{R E R, i}\right) & =\varepsilon_{i, t}^{R E R} .
\end{aligned}
$$

Here, $A_{i}(L)$ is a polynomial in the lag operator with roots inside the unit circle so that the $R E R$ is a stationary process. The parameter $\mu_{R E R, i}$ is the mean of $\log \left(R E R_{i, t}\right)$. The random variables

\footnotetext{
${ }^{12}$ Additional recent evidence against random-walk-based forecasts for the $N E R$ comes from Cheung, Chinn, Pascual, and Zhang (2017). Using a sample that spans different monetary policy regimes, they find that for some countries and some sub-samples, relative-PPP-based forecasts outperform the random-walk model.

${ }^{13}$ In Appendix A we provide t-statistics from a test studied in Diebold and Mariano (1995) and West (1996). The implications of the t-statistics are broadly similar to our bootstrap p-values. See Rossi (2005) for a discussion of the properties of the Diebold and Mariano (1995) test in an environment similar to ours.
} 
$\varepsilon_{i, t}^{N E R}$ and $\varepsilon_{i, t}^{R E R}$ are uncorrelated over time (though potentially correlated within a period). This DGP embeds the assumption that changes in the $N E R$ are unpredictable at all horizons. ${ }^{14}$ We consider up to 8 lags in $A_{i}(L)$ and choose the lag length separately for each country using the Akaike information criterion (AIC). Given the estimates of $A_{i}(L)$, we compute a time series for $\varepsilon_{i, t}^{R E R}$ and $\varepsilon_{i, t}^{N E R}$ from the data.

We jointly sample the disturbances to preserve contemporaneous correlations between the $N E R$ and $R E R$ and across countries. We construct 10,000 synthetic time series, each of length equal to the size of our sample, by randomly selecting a sequence of estimated disturbances from the period for which we have a balanced panel. Limiting the bootstrapping to this period preserves the covariance among the shocks. ${ }^{15}$ For each synthetic time series, we compute forecasts based on equation (4) and the random walk without drift. Using these forecasts, we compute RMSPEs for each country and for the pooled countries.

Panel (b) of Table 5 shows the percentage of bootstrap simulations in which the value of the relative RMSPE is less than or equal to the analogue number reported in panel (a) at different horizons. Consider the first row that pertains to the pooled results. For the three-year horizon, we can reject the random-walk hypothesis at a 5 percent significance level. At the four-, five-, and six-year horizons, we can reject the random-walk hypothesis at a 1 percent significance level.

Up to this point, we maintained the assumption that the $R E R$ is stationary. To assess the robustness of our results, we redo the out-of-sample bootstrap exercises assuming that $\log \left(R E R_{i, t}\right)$ is difference stationary. In particular, we assume that

$$
B_{i}(L)(1-L) \log \left(R E R_{i, t}\right)=\mu_{\Delta R E R, i}+\varepsilon_{i, t}^{R E R}
$$

Here, $B_{i}(L)$ is a polynomial in the lag operator with roots inside the unit circle and $\mu_{\Delta R E R, i}$ is the mean of the $\log$ difference of the $R E R$ for county $i$. We maintain the assumption that changes in the $N E R$ are given by equation (7). As before, we choose the lag length by the AIC and compute

\footnotetext{
${ }^{14}$ Note that if $\log \left(N E R_{i, t} / N E R_{i, t-1}\right)$ has a non-zero mean, that property is reflected in the fitted shocks from which we construct the bootstrap samples.

${ }^{15}$ We have a burn-in period of 1000 quarters so that the initial values of $\log \left(R E R_{i, t}\right)$ are different across bootstrap samples.
} 
the relative RMSPEs. The implied $p$-values are reported in panel (c) of Table 5 . The results are very similar to those reported in panel (b) of that table. We conclude that our results are not sensitive to whether or not we assume that the $R E R$ has a unit root.

The results in this section provide strong support for the view that the $N E R$ is forecastable at medium and long horizons. Based on this finding we infer that the in-sample correlations regressions in the previous section are not spurious.

\section{Interpreting our results in a simple economic model}

In this section, we use a simple endowment economy to highlight the roll of inflation targeting and home bias in generating our empirical findings. We work with flexible prices to emphasize that the results from this section do not depend on the presence of nominal rigidities. For analytical tractability, the model features a number of simplifying assumptions such as complete markets, UIP, and the law of one price. In the next section, we relax these assumptions and consider an estimated medium-scale DSGE model that incorporates nominal rigidities. It turns out that the intuition from our simple model carries over to our estimated model.

\subsection{Model setup}

The model consists of two symmetric countries which we refer to as home and foreign. To conserve space, we only display the relevant equations for the home country. The home country is populated by a representative household with lifetime utility, $U$, given by

$$
U=E_{0} \sum_{t=0}^{\infty} \beta^{t} \log \left(C_{t}\right)
$$

Here, $C_{t}$ denotes consumption of the home country and $E_{t}$ the expectations operator conditional on time- $t$ information, and $0<\beta<1$.

Households can trade in a complete set of domestic and international contingent claims. The 
domestic household's flow budget constraint is given by

$$
P_{t} C_{t}+B_{t}+N E R_{t} B_{t}^{*} \leq P_{Y, t} Y_{t}+R_{t-1} B_{t-1}+N E R_{t} R_{t-1}^{*} B_{t-1}^{*}+T_{t}
$$

Here, $P_{t}$ is the price of domestic consumption, $B_{t}$ and $B_{t}^{*}$ are nominal balances of home and foreign bonds, $R_{t}$ and $R_{t}^{*}$ are the nominal interest rate on the home and foreign bond, $N E R_{t}$ is the nominal exchange rate, defined as in our empirical section as the price of the foreign currency unit (units of home currency per unit of foreign currency). The variable $T_{t}$ denotes nominal lump-sum taxes and net proceeds from contingent claims. ${ }^{16}$ With complete markets, the presence of one-period nominal bonds is redundant since these bonds can be synthesized using state-contingent claims.

The output endowment of the home country, $Y_{t}$, follows the following exogenous law of motion:

$$
\log \left(Y_{t}\right)=\rho_{Y} \log \left(Y_{t-1}\right)+\varepsilon_{Y, t}
$$

where $\varepsilon_{Y, t}$ is an i.i.d. shock that follows a normal distribution.

The first-order conditions with respect to bond holdings are

$$
\begin{aligned}
& 1=\beta R_{t} E_{t} \frac{C_{t}}{\pi_{t+1} C_{t+1}}, \\
& 1=\beta R_{t}^{*} E_{t} \frac{C_{t}}{\pi_{t+1} C_{t+1}} \frac{N E R_{t+1}}{N E R_{t}} .
\end{aligned}
$$

Here, $\pi_{t} \equiv P_{t} / P_{t-1}$ denotes the inflation rate in the home country.

The home consumption good, $C_{t}$, is produced by combining domestic and foreign goods $\left(Y_{H, t}\right.$ and $Y_{F, t}$, respectively) according to the technology

$$
C_{t}=\left[\omega^{1-\rho} Y_{H, t}^{\rho}+(1-\omega)^{1-\rho} Y_{F, t}^{\rho}\right]^{\frac{1}{\rho}}
$$

Here, $0.5 \leq \omega<1$ controls the degree of home bias in consumption. The parameter $\rho<1$ controls the elasticity of substitution between home and foreign goods.

\footnotetext{
${ }^{16}$ Money holdings can easily be added to the model by including a separable additive term in the utility function and modifying the budget constraint accordingly.
} 
We define the $R E R_{t}$ as units of the home consumption good per one unit of the foreign consumption good,

$$
R E R_{t}=\frac{N E R_{t} P_{t}^{*}}{P_{t}}
$$

Here, $P_{t}^{*}$ is the foreign currency price of the foreign consumption good. With this definition, an increase in $R E R_{t}$ corresponds to a rise in the relative price of the foreign consumption good.

Complete markets and symmetry of initial conditions imply

$$
R E R_{t}=\frac{C_{t}}{C_{t}^{*}}
$$

Because prices are flexible, the law of one price holds, which means $P_{t}=P_{t}^{*} N E R_{t}$. Market clearing in the output market for the two countries requires $Y_{H, t}+Y_{H, t}^{*}=Y_{t}$ and $Y_{F, t}+Y_{F, t}^{*}=Y_{t}^{*}$. Here, the variable $Y_{H, t}^{*}$ denotes home output used in producing the foreign consumption good and $Y_{F, t}^{*}$ denotes foreign output used in producing the foreign consumption good. The variable $Y_{t}^{*}$ denotes the exogenous endowment of output in the home country. This endowment follows an AR(1) with first-order serial correlation $\rho_{Y}$ that is analogous to (12). Finally, we assume that both home and domestic bonds are in zero net supply.

In the home country the monetary authority sets the nominal interest rate according to the Taylor rule

$$
R_{t}=\beta^{-1} \pi_{t}^{\theta_{\pi}}
$$

We assume that the Taylor principle holds, so that $\theta_{\pi}>1$. We abstract from an output gap term in the Taylor rule because prices are flexible. ${ }^{17}$ Monetary policy in the foreign country is set in a symmetric manner.

\subsection{Model properties and regression coefficients}

In this section, we use the following parameter values. We set the value of $\beta$ so that the steadystate real interest rate is 3 percent. As in Backus et al. (1992), we assume that the elasticity of substitution between domestic and foreign goods in the consumption aggregator is $1.5(\rho=1 / 3)$.

\footnotetext{
${ }^{17}$ We discuss including an output gap in the Taylor rule in our estimated model in the next section.
} 
We assume that the import share is 15 percent $(\omega=0.85)$ so that there is home bias in consumption and we set $\rho_{Y}$, the first-order serial correlation of the endowment, equal to 0.95 .

Figure 2 displays the impulse response for a negative shock to the domestic endowment, $Y_{t}$. The $R E R$ falls in response to the shock, i.e the foreign consumption basket becomes cheaper relative to the domestic consumption basket. Home bias plays a critical roll in the $R E R$ movement. Recall that the $R E R$ is given by (17). So, the $R E R$ falls, reflecting the scarcity of home goods and the fact that the home consumption basket places a larger weight on home goods than the size of the home country $(\omega>0.5)$. Put differently, home consumption falls by more than foreign consumption because households in the home country consume more of the good that has become relatively scarce. If there was no home bias $(\omega=0.5)$, the $R E R$ would not change in response to the negative shock to $Y_{t}$.

Given the differential paths of consumption in the home and foreign country, household Euler equations imply that the domestic real interest rate must be higher than the foreign real interest rate. The Taylor rule and the Taylor principle imply that high real interest rates are associated with high nominal interest rates and high inflation rates. It follows that the nominal interest rate and the inflation rate in the home country rise by more than in the foreign country. This result is inconsistent with the naive intuition that inflation has to be lower in the home country in order for the $R E R_{t}$ to return to its pre-shock level. In fact, inflation is persistently higher in the home country. So $R E R_{t}$ reverts to its steady-state value via changes in $N E R_{t}$, not prices. This is inconsistent with naive intuition that differential inflation rates are the mechanism by which the $R E R$ returns to its pre-shock level. In fact, $N E R_{t}$ has to change by enough to offset both the initial movement in $R E R_{t}$ and the cumulative difference between the domestic and foreign inflation rates.

To further understand the dynamics of the $N E R$, it is useful to solve the log-linear version of the model. Combining the log-linearized Taylor rules, the intertemporal Euler equations (13), and the relation between the two countries' marginal utilities implied by complete markets (see equation (17)), we obtain

$$
\hat{\pi}_{t}-\hat{\pi}_{t}^{*}=-\frac{1-\rho_{Y}}{\theta_{\pi}-\rho_{Y}} \widehat{R E R} R_{t}
$$


where $\hat{x}_{t}$ is the log deviation of $x_{t}$ from its steady state value. Since the Taylor principle holds $\left(\theta_{\pi}>1\right)$, we have $\left|\frac{1-\rho_{A}}{\theta_{\pi}-\rho_{A}}\right|<1$. Given that $R E R_{t}=N E R_{t} P_{t}^{*} / P_{t}$, (19) implies that, on impact, $R E R_{t}$ falls by more than $P_{t}^{*} / P_{t}$. It follows that $N E R_{t}$ must initially fall, i.e., the currency in the home country appreciates on impact.

As shown in Figure 2, there is a persistent gap between $R_{t}$ and $R_{t}^{*}$, reflecting the persistence in $Y_{t}$. Since UIP holds in the log-linear equilibrium, the home currency must depreciate over time to compensate for the gap between $R_{t}$ and $R_{t}^{*}$. So the home currency appreciates on impact and then depreciates. This pattern is reminiscent of the overshooting phenomenon emphasized by Dornbusch (1976). ${ }^{18}$ Inflation in the home country is persistently higher than in the foreign country, so $P_{t}$ rises by more than $P_{t}^{*}$. This result, along with the law of one price, implies that the home country currency depreciates over time, converging to a value that is lower than its pre-shock value (see Figure (2)).

In the model, a low current value of $R E R_{t}$ predicts that the foreign currency appreciates in the future. So, the model implies that $\beta_{h}^{N E R}$ is negative. Moreover, it is increasing in absolute value with $h$ because the cumulative appreciation of the foreign currency increases over time. In the appendix we derive the probability limits (plims) of the regression coefficients, $\beta_{h}^{N E R}$ and $\beta_{h}^{\pi}$, implied by the log-linear model. These plims are given by

$$
\begin{aligned}
\beta_{h}^{N E R} & =-\frac{1-\rho_{Y}^{h}}{1-\rho_{Y} / \theta_{\pi}}, \\
\beta_{h}^{\pi} & =\frac{1-\rho_{Y}^{h}}{\theta_{\pi} / \rho_{Y}-1} .
\end{aligned}
$$

Equation (20) implies that $\beta_{h}^{N E R}$ is negative for all $h$ and increases in absolute value with $h$. So, for this shock, the model naturally accounts for the fact that our empirical estimates of $\beta_{h}^{N E R}$ are negative and increasing, in absolute value, as $h$ increases.

The more aggressive is monetary policy (i.e., the larger is $\theta_{\pi}$ ), the smaller is the absolute value of $\beta_{h}^{N E R}$. The intuition for this result is as follows. After a negative shock to $Y_{t}, \pi_{t}$ is higher than $\pi_{t}^{*}$. The higher is $\theta_{\pi}$, the lower is $\left|\pi_{t}-\pi_{t}^{*}\right|$ and the lower is the depreciation of the domestic

\footnotetext{
${ }^{18}$ In Dornbusch (1976), an unanticipated permanent change in the money supply causes the $N E R$ to overshoot relative to its new long-run level.
} 
currency needed to bring about the required adjustment in $R E R_{t}$. So the absolute value of $\beta_{h}^{N E R}$ is decreasing in $\theta_{\pi}$. Equation (21) implies that $\beta_{h}^{\pi}$ is positive for all $h$ and converges to $\rho_{Y} /\left(\theta_{\pi}-\rho_{Y}\right)$. Consistent with the previous intuition, the higher is $\theta_{\pi}$, the lower is $\beta_{h}^{\pi}$ for all $h$.

Interestingly, the plims of $\beta_{h}^{N E R}$ and $\beta_{h}^{\pi}$ do not depend on the exact value of $\omega$. The reason is that $\omega$ controls the size of the initial response of the $R E R$ to the shock, but not the dynamic properties thereafter. As a result, the plims of the regression coefficients, which relate future changes in the $N E R$ or relative prices to the current level of the $R E R$, are independent of $\omega$.

The sum of the two plims is given by

$$
\beta_{h}^{N E R}+\beta_{h}^{\pi}=-\left(1-\rho_{Y}^{h}\right)
$$

This sum converges to -1 as $h \rightarrow \infty$, reflecting the fact that $R E R_{t}$ must eventually converge to

its pre-shock steady-state level. While this sum converges to $-1, \beta_{h}^{N E R}$ converges to a value that is lower than -1 . These properties reflect the fact that $N E R_{t}$ must eventually adjust by more than $R E R_{t}$ to bring the latter back to its steady state value.

\section{Medium-Scale DSGE Model}

In this section, we address the following question: what shocks and frictions account quantitatively for the observed correlation between the current $R E R$ and future changes in the $N E R$ ? We answer this question by considering an estimated medium-scale DSGE model with three regions: the U.S., Germany, and the rest of the World. The model incorporates the two key features of our simple endowment economy analyzed in Section 4: home bias and inflation targeting in the form of a Taylor rule. Our analysis focuses on fluctuations in the bilateral exchange rate between the U.S. and Germany. Having three regions allows us to study bilateral exchange rates without implausible assumptions about import and export shares. 


\section{$5.1 \quad$ Households}

For notational ease, the U.S., Germany, and the rest of the World correspond to country 1, 2, and 3, respectively. Each country $i$ has a continuum of households of size $n_{i} \in(0,1)$. The size of the World population is equal to one: $n_{1}+n_{2}+n_{3}=1$. As is Christiano et al. (2005), each household makes three sets of decisions per period. First, each household decides how much to consume, how much capital to accumulate, and how much capital services to supply to the market. Second, each household purchases securities, whose payoffs are contingent on whether it can re-optimize its nominal wage rate. We assume that there are complete contingent claims markets within each country. Only U.S. dollar-denominated bonds can be traded internationally. Third, each household sets its nominal wage rate after finding out whether it can re-optimize it.

Since households face idiosyncratic risk about whether they can re-optimize their nominal wage rates, hours worked and wage rates differ across households. So, in principle households are heterogeneous with respect to consumption and asset holdings. It follows from a straightforward extension of arguments in Woodford (1998) and Erceg et al. (2000) that, in equilibrium, households in a given country are homogeneous with respect to consumption and asset holdings. Reflecting this result, our notation assumes that households are homogeneous with respect to consumption and asset holdings but heterogeneous with respect to their wage rate and hours worked.

Similar to Christiano et al. (2005), we assume that the utility of household $k$ in country $i$ is given by

$$
U_{k, i}=E_{0} \sum_{t=0}^{\infty} \beta^{t} \mu_{i, t}\left[\log \left(C_{i, t}-f \bar{C}_{i, t-1}\right)-\frac{\chi}{2} L_{i, t}(k)^{2}+\sum_{j=1}^{3} \log \left(\eta_{i, j, t}\right) V\left(\frac{B_{i, j, t}}{P_{i, t}} N E R_{i, j, t}\right)\right] .
$$

Here, $C_{i, t}$ is the consumption of each household in country $i$ and $\bar{C}_{i, t}$ is per-capita aggregate consumption. $L_{i, t}(k)$ are hours worked by household $k$ in country $i$. The scalar $f$ denotes the degree of habit formation in preferences. $B_{i, j, t}$ is end-of-period- $t$ holdings of country- $j$ bonds held by the households in country $i . P_{i, t}$ is the consumer price index in country $i$ denominated in local currency units. $N E R_{i, j, t}$ is the price of country- $j$ currency in units of country-i's currency. The variable $\mu_{i, t}$ is a shock to the household's discount rate. 
The function $V$ governs the utility flow from bond holdings of different countries. The variable $\eta_{i, j, t}$ is a shock to the utility that country $i$ derives from holding the bonds of country $j$. For convenience, we assume that $\eta_{i, j, t}$ is one in steady state, so that the steady-state utility flow from bonds is zero. Outside the steady state, there may be shocks that put a premium on one bond or another - those arising from flights to safety or liquidity, for example. This type of shock breaks UIP in log-linear versions of the model. We refer to $\eta_{i, j, t}$ as a spread shock. Instead of introducing a shock directly into the UIP condition, as in McCallum (1994), we assume that households derive utility from bond holdings and that this utility flow varies over time. Engel (2019) and Itskhoki and Mukhin (2017) argue that these type of shocks are important for understanding the empirical behavior of exchange rates. The latter provide an extensive discussion of the micro-foundations of these shocks. Our assumptions about $\eta_{i, j, t}$ below allow for the possibility of World-wide shocks to the marginal utility of holding dollar-denominated bonds or shocks to that marginal utility that only affect non-U.S. households.

The household budget constraint is

$$
\begin{gathered}
\sum_{i=\{1, i\}} B_{i, j, t} N E R_{i, j, t}+P_{i, t} C_{i, t}+P_{i, t} I_{i, t}+a_{i}\left(u_{i, t}\right) \bar{K}_{i, t} P_{i, t}+\varphi_{B, i, t}= \\
\sum_{j=\{1, i\}} R_{j, t-1} B_{i, j, t-1} N E R_{i, j, t}+R_{i, t}^{K} u_{i, t} \bar{K}_{i, t}+W_{i, t}(h) L_{i, t}(h)+T_{i, t},
\end{gathered}
$$

where

$$
\varphi_{B, i, t}=\mathbf{1}\{i \neq 1\} \Phi_{1, B}\left(\frac{B_{i, 1, t} N E R_{i, 1, t}}{P_{i, t}}\right) P_{i, t},
$$

$R_{i, t}^{K}$ is the rental rate on capital in country $i, \bar{K}_{i, t}$ is the stock of capital owned by the households in country $i, I_{i, t}$ is the household's investment in country $i, u_{i, t}$ is the capital utilization rate, $u_{i, t} \bar{K}_{i, t}$ denotes period- $t$ supply of capital services by the household, and $a_{i}\left(u_{i, t}\right) \bar{K}_{i, t}$ denotes the cost of capital utilization. $T_{i, t}$ are net receipts from all contingent claims of the household as well as lump-sum taxes, transfers, profits received from domestic firms. The function $\Phi_{i, B}$ refers to costs of holding foreign bonds. As in Schmitt-Grohé and Uribe (2003), we allow for this cost to avoid the presence of a unit root in real exchange rates. We assume that households do not pay a cost for holding bonds denominated in their home currency. The functional form for $a_{i}$ and $\Phi_{1, B}$ 
are described below. The budget constraint embodies our assumption that a country- $i$ household can hold bonds denominated in country- $i$ currency. In addition, households in every country can purchase dollar-denominated bonds. This assumption corresponds to the key empirical finding in Maggiori et al. (2018).

We assume that there are nominal wage rigidities, as modeled by Erceg et al. (2000). A labor aggregator combines labor services from each household to produce the homogeneous labor input used in production, $L_{i, t}$, according to

$$
L_{i, t}=\left(\frac{1}{n_{i}} \int_{0}^{n_{i}}\left(L_{i, t}(h)\right)^{\frac{\nu_{i, t}-1}{\nu_{i, t}}} d h\right)^{\frac{\nu_{i, t}}{\nu_{i, t}-1}}
$$

Household $h$ is a monopoly supplier of $L_{i, t}(h)$. The variable $W_{i, t}(h)$ represents the wages paid to household $h$. Labor aggregators are perfectly competitive and take the nominal wage for the homogeneous labor input, $W_{i, t}$, as given. With probability $1-\xi_{W, i}$, a household updates its wage rate to maximize the utility of the household. With probability $\xi_{W, i}$, the wage grows at its steady-state growth rate. The random variable $\nu_{i, t}$ controls the substitution between labor types.

The capital accumulation equation is

$$
\bar{K}_{i, t+1}=\zeta_{i, t} F_{i}\left(I_{i, t}, I_{i, t-1}\right)+(1-\delta) \bar{K}_{i, t}
$$

The variable $\zeta_{i, t}$ is an investment-specific technology shock. The function $F_{i}$ embeds the technology that transforms current and past investment into capital. We discuss the properties of $F$ below. The parameter $\delta$ controls the capital depreciation rate.

The final good is created by the household by combining goods from each country using the production function

$$
Y_{i, t}=\left(\sum_{j=1}^{3} \omega_{i, j}^{1-\rho}\left[\varphi_{i, j, t} Y_{i, j, t}\right]^{\rho}\right)^{\frac{1}{\rho}} .
$$

Here, $Y_{i, j, t}$ denotes purchases of wholesale goods produced from country $j$. The price of $Y_{i, j, t}$ in country $i$ 's currency is $P_{i, j, t}$. The parameters $\omega_{i, j}$ control the importance of goods from country 
$j$ in producing $Y_{i, t}$, and $\sum \omega_{i, j}=1 .{ }^{19}$ The term $\varphi_{i, j, t}$ represents adjustment costs associated with changing the ratio of imports to domestically produced goods. As in Erceg et al. (2006), we assume that

$$
\varphi_{i, j, t}=\left[1-\frac{\varphi_{i}}{2}\left(\frac{Y_{i, j, t} / Y_{i, i, t}}{Y_{i, j, t-1} / Y_{i, i, t-1}}-1\right)^{2}\right] .
$$

Erceg et al. (2006) argue that these adjustment costs enable the model to capture the relatively sluggish response to shocks of the share of imports in final goods.

\subsection{Producers}

The wholesale good, $Y_{i, j, t}$, is produced by perfectly competitive wholesalers using a continuum of intermediate goods according to the technology

$$
Y_{i, j, t}=\left(\frac{1}{n_{j}}\right)^{\frac{1}{v_{j, t}}}\left(\int_{0}^{n_{j}} X_{i, j, t}(m)^{\frac{v_{j, t}-1}{v_{j, t}}} d m\right)^{\frac{v_{j, t}}{v_{j, t}-1}}
$$

Here, $X_{i, j, t}(m)$ denotes purchases of the $m$ 'th intermediate good from country $j$ by the wholesaler in country $i$. The random variable $v_{j, t}$ controls the substitution between intermediate goods. Since this variable is indexed by $j$, we are assuming that a country- $j$ producer of intermediate good $m$ is affected by $v_{j, t}$ regardless of where the good is sold.

The intermediate good $X_{i, j, t}(m)$ is produced by a monopolist in country $j$ using the technology

$$
A_{j, t} K_{j, t}^{\alpha}(m)\left(L_{j, t}(m)\right)^{1-\alpha}=\sum_{i=1}^{3} X_{i, j, t}(m)
$$

The variables $K_{j, t}(m)$ and $L_{j, t}(m)$ denote the amount of capital and labor hired by monopolist $m$ in country $j$. The intermediate good producers set their price in the currency where their goods are sold (so-called "local-currency pricing"). With probability $1-\xi_{P, i}$, monopolist $m$ sets prices,

\footnotetext{
${ }^{19}$ We estimated a version of the model in which the $\omega_{i, j}$ 's are stochastic and obtained results that are similar to the benchmark case.
} 
$P_{j, i, t}(m)$, for $j=1,2,3$ to maximize profits, which are given by

$$
E_{0} \sum_{t=0}^{\infty} \beta^{t} \Lambda_{i, t}\left(\frac{N E R_{i, j, t} P_{j, i, t}(m)}{P_{i, t}}-M C_{i, t}\right) X_{j, i, t}(m)
$$

subject to wholesaler demand for the product. The variable $\Lambda_{i, t}$ is the marginal utility of the household in country $i$ during period $t$ and $M C_{i, t}$ is the monopolist's real marginal cost of producing $X_{i, j, t}(m)$. With probability $1-\xi_{P, i}$, monopolists increase their prices $P_{j, i, t}(m)$ by the steady-state inflation rate in country $j$.

\subsection{Monetary policy}

In country $i$, the monetary authority follows a Taylor rule given by

$$
\frac{R_{i, t}}{R_{i}}=\left(\frac{R_{i, t-1}}{R_{i}}\right)^{\gamma_{i}}\left(\left(\frac{\pi_{i, t}}{\pi_{i}^{*}}\right)^{\theta_{\pi, i}}\left(\frac{G D P_{i, t}}{G \tilde{D} P_{i, t}}\right)^{\theta_{G D P, i}}\right)^{1-\gamma_{i}} \exp \left(\varepsilon_{R, i, t}\right) \text { where } \theta_{i, \pi}>1
$$

Here, $\varepsilon_{R, i, t}$ is a monetary policy shock, $R_{i}$ is the steady-state nominal interest rate in country $i$, and $\pi_{i}^{*}$ is the target rate of inflation. $G D P_{i, t}$ is defined as the sum of consumption, investment, government purchases, and net exports. $G \tilde{D} P_{i, t}$ is the natural level of $G D P_{i, t}$, defined as the level of $G D P_{i, t}$ that would prevail under flexible prices. ${ }^{20}$ In formulating the Taylor rule in terms of $G \tilde{D} P_{i, t}$, we are proceeding in the spirit of Woodford (2011) and Smets and Wouters (2007). Throughout, we assume that the Taylor principal is satisfied so that $\theta_{\pi, i}>1$. We also assume that $0 \leq \gamma_{i}<1$

\subsection{Final-good market clearing, bond market clearing, and equilibrium}

Market clearing for final good $Y_{i, t}$ implies

$$
C_{i, t}+G_{i, t}+I_{i, t}+a_{i}\left(u_{i, t}\right) \bar{K}_{i, t}+\mathbf{1}\{i \neq 1\} \Phi_{B, 1}\left(\frac{B_{i, 1, t} N E R_{i, 1, t}}{P_{i, t}}\right)=Y_{i, t}
$$

\footnotetext{
${ }^{20}$ As in Smets and Wouters (2007), we assume that monetary policy shocks, price markup shocks, and wage markup shocks are not operative in the flexible-price equilibrium.
} 
where $G_{i, t}$ are government purchases of goods in country $i$. We assume that the government balances its budget in each period with lump-sum taxes. As a result, dollar-denominated bonds are in zero net supply, so

$$
\sum_{j=1}^{3} n_{j} B_{j, 1, t}=0
$$

We adopt a standard sequence-of-markets equilibrium concept. We work with a standard log-linear approximation around the symmetric balanced-growth steady state. In Appendix E we derive and display the equations whose solution defines the equilibrium for our model economy. Included among these equations are the first-order conditions to the optimizations of all of the firms and households in each country.

\subsection{Stochastic processes}

In this section, we describe our assumptions about the shocks impacting the environment. Even though we allow for many shocks, it turns out that only a small subset of the shocks are quantitatively important drivers of the equilibrium exchange rate. Our approach allows us to identify these shocks.

In what follows, $\varepsilon_{\cdot, i, t}$ are iid normal random variables and $\left|\rho_{\cdot, i}\right|<1$. The aggregate technology shock $A_{i, t}$ in equation (31) follows a trend-stationary process with a global stochastic component $\left(A_{t}\right)$ and a country-specific component $\left(\tilde{A}_{i, t}\right)$. In particular, we assume that

$$
A_{i, t}=\tilde{A}_{i, t} A_{t} \Upsilon^{t(1-\alpha)}
$$

The variable $\Upsilon$ is the unconditional growth rate in balanced-growth equilibrium.

We assume that $A_{t}, \tilde{A}_{i, t}$, the shock to the household rate of time discount, $\mu_{i, t}$, in equation (23), the investment-specific technology shock, $\zeta_{i, t}$, in equation (27), and the government purchases shock, $G_{i, t}$, in equation (34) evolve according to

$$
\log \left(x_{i, t}\right)=\rho_{x, i} \log \left(x_{i, t-1}\right)+\varepsilon_{x, i, t}
$$


Here, $x_{i, t}$ is the ratio of the variable to its steady-state value. The variables $\frac{\nu_{i, t}}{\nu_{i, t}-1}$ and $\frac{v_{j, t}}{v_{j, t}-1}$, which act as wage and price markup shocks, also evolve according to (37).

The spread shocks, $\eta_{i, j, t}$, evolve according to

$$
\eta_{i, j, t}=\tilde{\eta}_{i, j, t} \eta_{j, t}
$$

Recall that $\eta_{i, j, t}$ is a shock to the marginal utility in country $i$ from holding a country- $j$ bond. According to our specification, a change in $\eta_{i, j, t}$ can reflect a change in the marginal utility of a country- $i$ household for country- $j$ bonds (through $\tilde{\eta}_{i, j, t}$ ) or a World-wide increase in the marginal utility of holding country- $j$ bonds (through $\eta_{j, t}$ ). The random variables $\eta_{j, t}$ evolve according to (37). We assume that the only $\tilde{\eta}_{2,1, t}$ and $\tilde{\eta}_{3,1, t}$ are potentially non-zero. For simplicity, we assume that $\tilde{\eta}_{2,1, t}=\tilde{\eta}_{3,1, t}=\tilde{\eta}_{t}$. For all other combinations of $i$ and $j, \tilde{\eta}_{i, j, t}$ is zero. These assumptions allow us to identify $\eta_{j, t}$ and reflect the special role that U.S. bonds play in the model. The variables $\eta_{j, t}$ and $\tilde{\eta}_{i, j, t}$ evolve according to $(37)$.

Since we only include global output as an observable variable for the rest of the World (see below), we set a number of shocks in the third country to zero. In particular, we set $\mu_{3, t}, \zeta_{3, t}, G_{3, t}$, $\nu_{3, t}, v_{3, t}$, and $\eta_{3, t}$ to their unconditional steady state values. So, the only shocks originating from the rest of the World are $\tilde{\eta}_{3,1, t}$ and $\tilde{A}_{3, t}$, i.e. shocks to the demand for dollar-denominated bonds and technology.

\subsection{Functional forms}

As in Christiano et al. (2005), we assume the function form for investment adjustment costs is given by

$$
F_{i}\left(I_{i, t}, I_{i, t-1}\right)=I_{i, t}\left(1-S_{i}\left(\frac{I_{i, t}}{I_{i, t-1} \Upsilon}\right)\right)
$$

where $S_{i}(1)=S_{i}^{\prime}(1)=0$ and $S_{i}^{\prime \prime}(1)>0 .{ }^{21}$ These properties of $S_{i}$ are the only ones relevant for the log-linear equilibrium conditions.

We assume that $a_{i}(1)=0$ and that $u_{i, t}=1$ in steady state. The only other feature of $a$ that

\footnotetext{
${ }^{21}$ See Eberly et al. (2012) for firm-level evidence consistent with this form of investment adjustment costs.
} 
is relevant in the log-linear equilibrium is $a_{i}^{\prime \prime}(1) / a_{i}^{\prime}(1)>0$, which we treat as a parameter to be estimated.

We assume that the function $V$ is increasing and strictly concave. The only property of $V$ that is relevant for the log-linear equilibrium conditions is $V^{\prime}(0)$, which we set equal to the steady-state value of $\Lambda_{i, t}$. This assumption amounts to a normalization according to which that $\eta_{i, j, t}$ enters the intertemporal Euler equation with a coefficient of unity.

Finally, we assume that the cost of holding bonds, $\Phi_{B, 1}$, is given by

$$
\Phi_{B, 1}(b)=\frac{\psi_{b} \Upsilon^{t}}{2}\left(\frac{b}{\Upsilon^{t}}\right)^{2} .
$$

In our economy, shocks cause borrowing and lending among countries. The magnitude of that borrowing and lending reflects growth in economy-wide variables, like real GDP. We scale real bond holdings by $\Upsilon^{t}$ so that the adjustment costs do not rise as the economy grows.

\section{Estimation}

In this section we accomplish three tasks. First, we discuss the data used in our analysis and our estimation procedure. Second, we discuss parameters that we fix a priori. Third, we discuss the parameters that we estimate using Bayesian methods (see An and Schorfheide (2007)).

\subsection{Data}

We estimate the model using data for the U.S. and Germany for the following variables: the growth rate of per-capita consumption, GDP, and investment, the real wage, the short-term interest rate, the rate of inflation, and the exchange rate between the U.S. and Germany. We also include data on hours worked in the U.S. and global GDP. See Appendix B for a detailed description of our data series. 


\subsection{Model parameters}

We set the markup parameters to $\nu_{i}=21$ and $v_{i}=6$, which are in the range considered by Altig et al. (2011). We calibrate the steady-state ratio of government purchases to output to 0.18. Consistent with the literature, we set $\alpha=0.25, f=0.75, \beta=0.9968$, and $\delta=0.025$.

We set $\Upsilon$, the unconditional quarterly growth rate of output, to the average quarterly growth rate of per-capita output across the U.S. and Germany in our sample (1.0046). Since we are working with a log-linear version of the model, the target inflation rates for the U.S., Germany, and the rest of the World do not affect the empirical analysis.

Because of data limitations, we set the following rest-of-the-World parameters to the common mean of the priors for the corresponding U.S. and German parameters: $S_{3}^{\prime \prime}(1)=4, \frac{a_{3}^{\prime \prime}(1) / a_{3}^{\prime}(1)}{a_{3}^{\prime \prime}(1) / a_{3}^{\prime}(1)+1}=$ $0.5, \gamma_{3}=0.75, \theta_{\pi, 3}=1.7, \theta_{G D P, 3}=0.1, \varphi_{3}=10$. In addition, we set the Calvo parameters $\left(\xi_{P, 3}\right.$ and $\left.\xi_{W, 3}\right)$ so that prices and wages are optimized on average once per year.

The remaining parameters are estimated using standard Bayesian methods. Tables 6, 7, and 8 display our prior distributions, as well as the posterior mode, posterior standard deviation, and the interval between the 5th and 95th percentile of the posterior distribution. ${ }^{22}$ Several features are worth noting. First, the model estimates imply fairly standard values for the Taylor rule coefficient for both the U.S. and Germany. Second, the posterior distribution of shock variances is fairly tightly estimated relative to the prior distributions. Third, there are some differences between the parameter estimates specific to the U.S. and the parameter estimates specific to Germany. In particular, the persistence of the marginal efficiency of investment is much lower in Germany than in the U.S., while the persistence of technology shocks are higher in Germany.

\subsection{Analysis}

We next turn to the question: what shocks and frictions account quantitatively for the movements in the $R E R$ and the $N E R$ as well as their covariance with inflation?23 We begin by quantifying

\footnotetext{
${ }^{22}$ We normalize the markup shocks, the marginal utility of consumption shocks, the marginal efficiency of investment shocks, and the spread shocks as explained in our Appendix. We use a Metropolis-Hasting algorithm to simulate draws from the posterior distribution of the parameters. We draw two chains of length 200,000 from the posterior distribution and discard the first 100,000 draws from each chain. We then keep every fifth draw.

${ }^{23}$ Throughout this section statistics are computed for the logarithm of the relevant variables.
} 
which shocks drive the volatility in the $R E R$ between the U.S. and Germany. Table 9 reports the fraction of the variance, at different frequencies, of the $R E R$ accounted for by the eight most important shocks. The variation of the $R E R$ is overwhelmingly accounted for by the shock to foreign demand for dollar-denominated bonds $\left(\tilde{\eta}_{t}\right)$. This shock alone accounts for roughly 75 percent of the variation in the $R E R$ at business cycle frequency. So, from the perspective of the model, almost all of the variance of the $R E R$ arises from spread shocks that affecting the difference in yields between U.S. and foreign bonds.

To provide further intuition behind the impact of a shock to foreign demand for dollardenominated bonds, Figure 3 displays the impulse response functions of different variables to an increase in $\tilde{\eta}_{t}$. A positive shock corresponds to an increase in foreign demand for dollar-denominated bonds. So, the dollar appreciates $\left(N E R_{1, j, t}\right.$ falls $)$ and the interest rate on dollar-denominated bonds $\left(R_{1, t}\right)$ falls. The Taylor rule and the appreciation of the dollar lead to a fall in U.S. inflation. Because of sticky prices, the fall in inflation is relatively small so that $R E R_{1, j, t}$ falls (i.e. the U.S. RER appreciates). Since $R_{1, t}$ falls and U.S. demand for dollar-denominated bonds is not directly affected by $\tilde{\eta}_{t}$, the U.S. finances a rise in consumption and investment by borrowing from the rest of the World ( $b_{1,1, t}$ falls). Because of habit formation and adjustment costs, U.S. consumption, investment, and real GDP rise and then decline in a hump-shaped pattern. In the foreign economies, export revenues rise because of the appreciation of the dollar and local-currency pricing. The increase in export revenue offsets some of the foreign households' desire to save in the form of dollar-denominated bonds. So, on net, there is a relatively small increase in foreign holdings of dollar-denominated bonds.

A key question is: which shock, in practice, accounts for the covariance between the $R E R$ and future changes in the $N E R$ ? This covariance is related to the the regression coefficient $\beta_{i, h}^{N E R}$, in (2) via the relationship

$$
\beta_{i, h}^{N E R}=\frac{\operatorname{cov}\left(R E R_{i, t}, \Delta^{h} N E R_{i, t+h}\right)}{\operatorname{var}\left(R E R_{i, t}\right)}=\frac{\sum_{\epsilon} \operatorname{cov}\left(R E R_{i, t}^{\epsilon}, \Delta^{h} N E R_{i, t+h}^{\epsilon}\right)}{\operatorname{var}\left(R E R_{i, t}\right)}
$$

where the sum is over the shocks. Table 12 reports the results of decomposing this covariance by shock. Note that at all horizons reported, roughly 70 percent of the negative covariance is due to 
$\tilde{\eta}_{t}$, the shock to foreign demand for dollar-denominated bonds.

Tables 10 and 11 report the fraction of the cyclical variation in GDP as measured by its deviation from trend for the U.S. and Germany at different frequencies. The key result is that shocks to foreign demand for dollar-denominated bonds account for less than 10 percent of the cyclical variation in GDP at business cycle frequency. The shocks that drive this variation are similar to those highlighted by Smets and Wouters (2007), e.g. shocks to the marginal efficiency of investment, markup shocks, and shocks to the domestic demand for dollar bonds $\left(\eta_{1, t}\right)$. In a closed-economy context, $\eta_{1, t}$ plays a very similar role of the risk-premium shock in Smets and Wouters (2007). Both shocks amount to a wedge in the intertemporal Euler equation for the risk-free asset. According to the model, technology shocks drive the bulk of cyclical variation in German real GDP. So, in our model, shocks to foreign demand for dollar-denominated bonds are an important driver of the $R E R$ without being an important driver of cyclical output fluctuations. This finding is consistent with the arguments in Itskhoki and Mukhin (2017).

The previous results are interesting to the extent that our model is a credible representation of the data. Our estimated model has a number of quantitative of properties that lend support to its credibility. We begin by showing that our estimated model can quantitatively account for the estimated values of $\beta_{i, h}^{N E R}$ and $\beta_{i, h}^{\pi}$ in regressions (2) and (3). To this end, we simulate our estimated model, drawing shocks from the estimated distributions, and run those regressions on the simulated data. The row labeled asymptotic value in Table 13 refers to regressions run on a time series of length 1,000,000 and the row labeled small sample refers to the mean of the estimates from 10,000 regressions run on simulated time series, each of length 100 . The row labeled standard deviation refers to the standard deviation of the estimates across the 10,000 regressions. Notice that the model accounts for the negative values of $\beta_{i, h}^{N E R}$, which grow in absolute value with horizon. The estimated values of $\beta_{i, h}^{\pi}$ are all small in absolute value and statistically insignificantly different from zero.

In the Appendix, Table 27 reports the values of $\beta_{i, h}^{N E R}$ and $\beta_{i, h}^{\pi}$ derived from simulating the model one shock at a time. In Section 4, we argued that as long as there is home bias and inflation-targeting policy (like a Taylor rule), the model implies qualitative patterns for $\beta_{i, h}^{N E R}$ and 
$\beta_{i, h}^{\pi}$ that are similar to those in the data. Our single-shock simulations are consistent with this argument.

Our estimated model also accounts for the volatility of the $R E R$ and $N E R$. In the data the standard deviation of both $\triangle N E R$ and $\triangle R E R$ is roughly 4.7 percent per quarter. The corresponding model statistics are 4.9 and 4.8 percent, respectively. The model accounts for Mussa (1986)'s observation that changes in the $R E R$ and the $N E R$ are highly correlated. The correlation between $\triangle N E R$ and $\triangle R E R$ is 0.99 in our data and 0.98 in the model. The model also does reasonably well at accounting for the persistence of the $R E R$. In the data the autocorrelation of $R E R$ is 0.96 while in the model it is 0.91 .

We now provide two additional pieces of evidence in favor of the model's empirical credibility. The first pertains to the "Backus-Smith puzzle." Backus and Smith (1993) document that the RER is at best weakly correlated with relative consumption across countries. However, many models counterfactually imply a high, positive correlation between the $R E R$ and relative consumption. This property is easily seen from equation (17) which pertains to a version of the model with complete markets. In our model, the conditional correlation between relative consumption and the $R E R$ is negative for $\tilde{\eta}_{t}$ but positive for most other shocks. After an increase in $\tilde{\eta}_{t}$, the $R E R$ falls, but U.S. consumption rises (see Figure 3). Itskhoki and Mukhin (2017) make a similar observation. To compute the unconditional correlation, we simulate the estimated model using the fitted disturbances of all the shocks and run the following regression

$$
\widehat{R E R} R_{1,2, t}=a_{0}+a_{1}\left(\hat{C}_{1, t}-\hat{C}_{2, t}\right)+\epsilon_{t}
$$

The plim of $a_{1}$ implied by our model is equal to 0.19 . The estimated value of $a_{1}$ in our data sample is -0.02 with a standard error of 0.29 . So taking sampling uncertainty into account, our estimated model is quantitatively consistent with the observed co-movement between the $R E R$ and relative consumption.

We now turn to the model's implications for the so-called "forward-premium puzzle" originally documented by Fama (1984). The issue is that many models counterfactually imply that the interest rate differential predicts changes in the $N E R$. This property is easily seen from a log- 
linear version of equations (13) and (14), which imply that the expected change in a bilateral $N E R$ is equal to the interest rate differential on bonds denominated in the two currencies, i.e. UIP holds. In contrast, according to our estimated model, UIP does not hold conditional on shocks to $\tilde{\eta}_{t}, \eta_{1, t}$, or $\eta_{2, t}$. For example, in Figure 3 , after a positive shock to $\tilde{\eta}_{t}, R_{1, t}$ is persistently lower than $R_{2, t}$, but the dollar depreciates over time. However, UIP holds for many of the other shocks in our model, like disturbances to technology. To determine whether our model can quantitatively account the failure of the standard, unconditional version of UIP, we simulated the estimated model using the fitted shocks. We then ran so-called "Fama regression," on the simulated time series:

$$
\Delta \widehat{N E} R_{1,2, t+1}=d_{0}+d_{1}\left(\hat{R}_{1, t}-\hat{R}_{2, t}\right)+\epsilon_{t}
$$

Fama (1984) rejects the null hypothesis that $d_{1}=1$. The plim of $d_{1}$ implied by our model is equal to 0.01 . The estimated value of $d_{1}$ in our data sample is -0.66 with a standard error of 0.74 . So taking sampling uncertainty into account, our model is quantitatively consistent with the observed co-movements between interest rate differentials and exchange rates.

\subsection{Exploring alternative monetary policy regimes}

In this subsection, we consider how the economy would have behaved under alternative monetary policy regimes. We consider two alternative policy regimes. In the first regime the monetary authority gives some weight to stabilizing the $N E R$. We refer to this policy as the $N E R$-targeting regime. In the second regime we model capital controls as large costs to foreign bond holdings, that is a large value of $\psi_{b}$ in equation (40). We refer to this policy as the capital-control regime.

In the $N E R$-targeting regime, the monetary policy rule is given by

$$
\frac{R_{i, t}}{R_{i}}=\left(\frac{R_{i, t-1}}{R_{i}}\right)^{\gamma_{i}}\left(\left(\frac{\pi_{i, t}}{\pi_{i}^{*}}\right)^{\theta_{\pi, i}}\left(\frac{G D P_{i, t}}{G \tilde{D} P_{i, t}}\right)^{\theta_{G D P, i}}\right)^{1-\gamma_{i}} N E R_{i, 1, t}^{\theta_{N E R, i}} \exp \left(\varepsilon_{R, i, t}\right)
$$

where $\theta_{N E R, i}>0 .^{24}$ According to equation (44), the monetary authority raises the nominal interest rate when the domestic currency depreciates. The larger is $\theta_{N E R, i}$, the higher the weight

\footnotetext{
${ }^{24}$ We assume that country $i$ adopts an inflation target that is equal to the U.S. inflation target.
} 
the monetary authority gives to stabilizing the exchange rate. As $\theta_{N E R, i} \rightarrow \infty$, this rule essentially becomes a fixed exchange rate regime.

To assess the impact of the change in monetary policy on exchange rates, we focus on the implications for $\beta_{i, h}^{N E R}$ and $\beta_{i, h}^{\pi}$. To this end, we generate artificial time series from our estimated model, but assume that German monetary policy is governed by equation (44) with $\theta_{N E R, i}=$ 0.1. The latter assumption implies that a 10 percent depreciation of the German currency is accompanied by a 1 percent increase in the German nominal interest rate. Table 14 reports the model-implied plims for $\beta_{i, h}^{N E R}$ and $\beta_{i, h}^{\pi}$, as well as the implied small sample means. The values of $\beta_{i, h}^{N E R}$ are much smaller than in our benchmark model, and the values of $\beta_{i, h}^{\pi}$ are much larger. These results imply that the $R E R$ is adjusting, over time, primarily through differential inflation rates, not through changes in the NER. The reason is that the monetary policy authority does let the $N E R$ change by as much as it does in the estimated model.

Under the NER-targeting regime, differential inflation rates much play a larger role in reestablishing long-run PPP. Interestingly, the persistence of the $R E R$ as measured by its first-order auto correlation rises from 0.91 under inflation targeting to 0.96 under the $N E R$-targeting regime. In this sense, inflation targeting results in more-rapid adjustment of the $R E R$ to its long-run value.

To capture the effects of capital controls, we assume that the cost to German households of holding dollar-denominated bonds $\left(\psi_{b}\right)$ is 100 times larger than in our estimated model. Under this assumption, the peak rise in German holdings of dollar-denominated bonds after a shock to $\tilde{\eta}_{t}$ is less than half of what it is in our benchmark estimated model. The larger is the cost of holding dollar-denominated bonds, the closer the German economy is to financial autarky.

As above, we focus on the implications for $\beta_{i, h}^{N E R}$ and $\beta_{i, h}^{\pi}$. To this end, we generate artificial time series from our estimated model, but assume that the costs to Germans of holding dollardenominated bonds are higher. Table 15 reports the model-implied plims for $\beta_{i, h}^{N E R}$ and $\beta_{i, h}^{\pi}$, as well as the implied small sample means. The values of $\beta_{i, h}^{N E R}$ and $\beta_{i, h}^{\pi}$ are similar to the estimates obtained in our benchmark model. In this sense, the latter estimates are robust to allowing for modest capital controls. 


\section{Conclusion}

This paper shows that in inflation-targeting countries, the $R E R$ adjusts to shocks in the medium and long run through changes in the $N E R$, not via differences in inflation rates. For such countries, the current $R E R$ is useful for forecasting future changes in the $N E R$. Consistent with the Lucas (1976) critique, these facts depend critically on the monetary policy regime in effect.

Using a simple endowment economy, we provide intuition for the economics underlying our statistical findings. This intuition relies on two key assumptions: the monetary authority follows an inflation-targeting policy like a Taylor rule and there is home bias in consumption. Home bias in consumption is important to generate movements in the $R E R$. Taylor rules are important because they keep inflation relatively stable and cause relative prices to move in such a way so that the $N E R$ has to adjust by more than the $R E R$ over time.

We build and estimate a medium-scale open-economy DSGE model to answer the question: what shocks and frictions account quantitatively for the movements in the $R E R$ and the $N E R$ as well as their covariance with inflation? We find that shocks to the foreign demand for dollardenominated bonds drive the bulk of exchange rate movements. These shocks also quantitatively account for the dynamic correlations that drive the predictability of the $N E R$. We argue that our inferences are credible because the model reproduces key empirical facts about the $N E R$ and $R E R$ as well as aggregate economic fluctuations.

\section{References}

David Altig, Lawrence J. Christiano, Martin Eichenbaum, and Jesper Linde. Firm-specific capital, nominal rigidities and the business cycle. Review of Economic dynamics, 14(2):225-247, 2011.

Manuel Amador, Javier Bianchi, Luigi Bocola, and Fabrizio Perri. Exchange rate policies at the zero lower bound. Technical report, National Bureau of Economic Research, 2017.

Sungbae An and Frank Schorfheide. Bayesian analysis of dsge models. Econometric reviews, 26 $(2-4): 113-172,2007$.

David K Backus and Gregor W Smith. Consumption and real exchange rates in dynamic economies with non-traded goods. Journal of International Economics, 35(3-4):297-316, 1993. 
David K Backus, Patrick J Kehoe, and Finn E Kydland. International real business cycles. Journal of political Economy, 100(4):745-775, 1992.

Marianne Baxter and Alan C Stockman. Business cycles and the exchange-rate regime: some international evidence. Journal of monetary Economics, 23(3):377-400, 1989.

Ben S Bernanke and Ilian Mihov. What does the bundesbank target? European economic review, 41(6):1025-1053, 1997.

Yin-Wong Cheung, Kon S Lai, and Michael Bergman. Dissecting the ppp puzzle: the unconventional roles of nominal exchange rate and price adjustments. Journal of International Economics, 64(1):135-150, 2004.

Lawrence J Christiano, Martin Eichenbaum, and Charles L Evans. Nominal rigidities and the dynamic effects of a shock to monetary policy. Journal of political Economy, 113(1):1-45, 2005.

Richard Clarida, Jordi Galı, and Mark Gertler. Monetary policy rules in practice: some international evidence. european economic review, 42(6):1033-1067, 1998.

Francis X Diebold and Robert S Mariano. Comparing predictive accuracy. Journal of Business 86 economic statistics, 13:253-263, 1995.

Janice Eberly, Sergio Rebelo, and Nicolas Vincent. What explains the lagged-investment effect? Journal of Monetary Economics, 59(4):370-380, 2012.

Charles Engel. Real exchange rate convergence: The roles of price stickiness and monetary policy. Journal of Monetary Economics, 2018.

Charles Engel, Nelson C Mark, and West. Exchange rate models are not as bad as you think. NBER macroeconomics annual, 22:381-473, 2007.

Christopher J Erceg, Dale W Henderson, and Andrew T Levin. Optimal monetary policy with staggered wage and price contracts. Journal of monetary Economics, 46(2):281-313, 2000.

Christopher J. Erceg, Luca Guerrieri, and Christopher Gust. SIGMA: A New Open Economy Model for Policy Analysis. International Journal of Central Banking, 2(1), March 2006.

Eugene F Fama. Forward and spot exchange rates. Journal of monetary economics, 14(3):319-338, 1984.

Jan JJ Groen. Exchange rate predictability and monetary fundamentals in a small multi-country panel. Journal of Money, Credit and Banking, pages 495-516, 2005.

Dale W Henderson and Warwick J McKibbin. A comparison of some basic monetary policy regimes for open economies: implications of different degrees of instrument adjustment and wage persistence. In Carnegie-Rochester Conference Series on Public Policy, volume 39, pages 221-317. Elsevier, 1993.

Ethan Ilzetzki, Carmen M Reinhart, and Kenneth S Rogoff. Exchange arrangements entering the 21st century: Which anchor will hold? Technical report, National Bureau of Economic Research, $2017 \mathrm{a}$. 
Ethan Ilzetzki, Carmen M. Reinhart, and Kenneth S. Rogoff. The country chronologies to exchange rate arrangements into the 21st century: Will the anchor currency hold? Mimeo, $20172017 \mathrm{~b}$.

Oleg Itskhoki and Dmitry Mukhin. Exchange rate disconnect in general equilibrium. Technical report, National Bureau of Economic Research, 2017.

Zhengyang Jiang, Arvind Krishnamurthy, and Hanno Lustig. Foreign safe asset demand and the dollar exchange rate. Technical report, National Bureau of Economic Research, 2018.

Robert Kollmann, Beatrice Pataracchia, Rafal Raciborski, Marco Ratto, Werner Roeger, and Lukas Vogel. The post-crisis slump in the euro area and the us: Evidence from an estimated three-region dsge model. European Economic Review, 88:21-41, 2016.

Thomas Lubik and Frank Schorfheide. A bayesian look at the new open economy macroeconomics, innber macroeconomics annual 2005, volume 20', 2006.

Robert E. Lucas. Econometric policy evaluation: A critique. In Carnegie-Rochester conference series on public policy, volume 1, pages 19-46, 1976.

Matteo Maggiori, Brent Neiman, and Jesse Schreger. International currencies and capital allocation. Technical report, National Bureau of Economic Research, 2018.

Nelson C. Mark. Exchange rates and fundamentals: Evidence on long-horizon predictability. The American Economic Review, pages 201-218, 1995.

Nelson C Mark and Donggyu Sul. Nominal exchange rates and monetary fundamentals: evidence from a small post-bretton woods panel. Journal of international economics, 53(1):29-52, 2001.

Nelson C Mark and Donggyu Sul. When are pooled panel-data regression forecasts of exchange rates more accurate than the time-series regression forecasts? Handbook of Exchange Rates, pages 265-281, 2011.

Bennett T McCallum. A reconsideration of the uncovered interest parity relationship. Journal of Monetary Economics, 33(1):105-132, 1994.

Richard A Meese and Kenneth Rogoff. Empirical exchange rate models of the seventies: Do they fit out of sample? Journal of international economics, 14(1-2):3-24, 1983.

Tanya Molodtsova and David H Papell. Out-of-sample exchange rate predictability with taylor rule fundamentals. Journal of international economics, 77(2):167-180, 2009.

Michael Mussa. Nominal exchange rate regimes and the behavior of real exchange rates: Evidence and implications. In Carnegie-Rochester Conference series on public policy, volume 25, pages 117-214. Elsevier, 1986.

Whitney K. Newey and Kenneth D. West. A simple, positive semi-definite, heteroskedasticity and autocorrelation consistent covariance matrix. Econometrica, 55(3):703-708, 1987.

Kenneth Rogoff. The purchasing power parity puzzle. Journal of Economic literature, 34(2): 647-668, 1996. 
Barbara Rossi. Testing long-horizon predictive ability with high persistence, and the meese-rogoff puzzle. International Economic Review, 46(1):61-92, 2005.

Barbara Rossi. Exchange rate predictability. Journal of economic literature, 51(4):1063-1119, 2013.

Lucio Sarno and Giorgio Valente. Deviations from purchasing power parity under different exchange rate regimes: Do they revert and, if so, how? Journal of Banking $\&$ Finance, 30(11):3147-3169, 2006.

Stephanie Schmitt-Grohé and Martın Uribe. Closing small open economy models. Journal of international Economics, 61(1):163-185, 2003.

Frank Smets and Raf Wouters. An estimated dynamic stochastic general equilibrium model of the euro area. Journal of the European economic association, 1(5):1123-1175, 2003.

Frank Smets and Rafael Wouters. Shocks and frictions in us business cycles: A bayesian dsge approach. American economic review, 97(3):586-606, 2007.

Alan M Taylor and Mark P Taylor. The purchasing power parity debate. Journal of economic perspectives, 18(4):135-158, 2004.

Kenneth D West. Asymptotic inference about predictive ability. Econometrica: Journal of the Econometric Society, pages 1067-1084, 1996.

M. Woodford. Interest and Prices: Foundations of a Theory of Monetary Policy. Princeton University Press, 2011.

Michael Woodford. Control of the public debt: a requirement for price stability? In The Debt Burden and Its Consequences for Monetary Policy, pages 117-158. Springer, 1998. 
Figure 1: NER and RER data
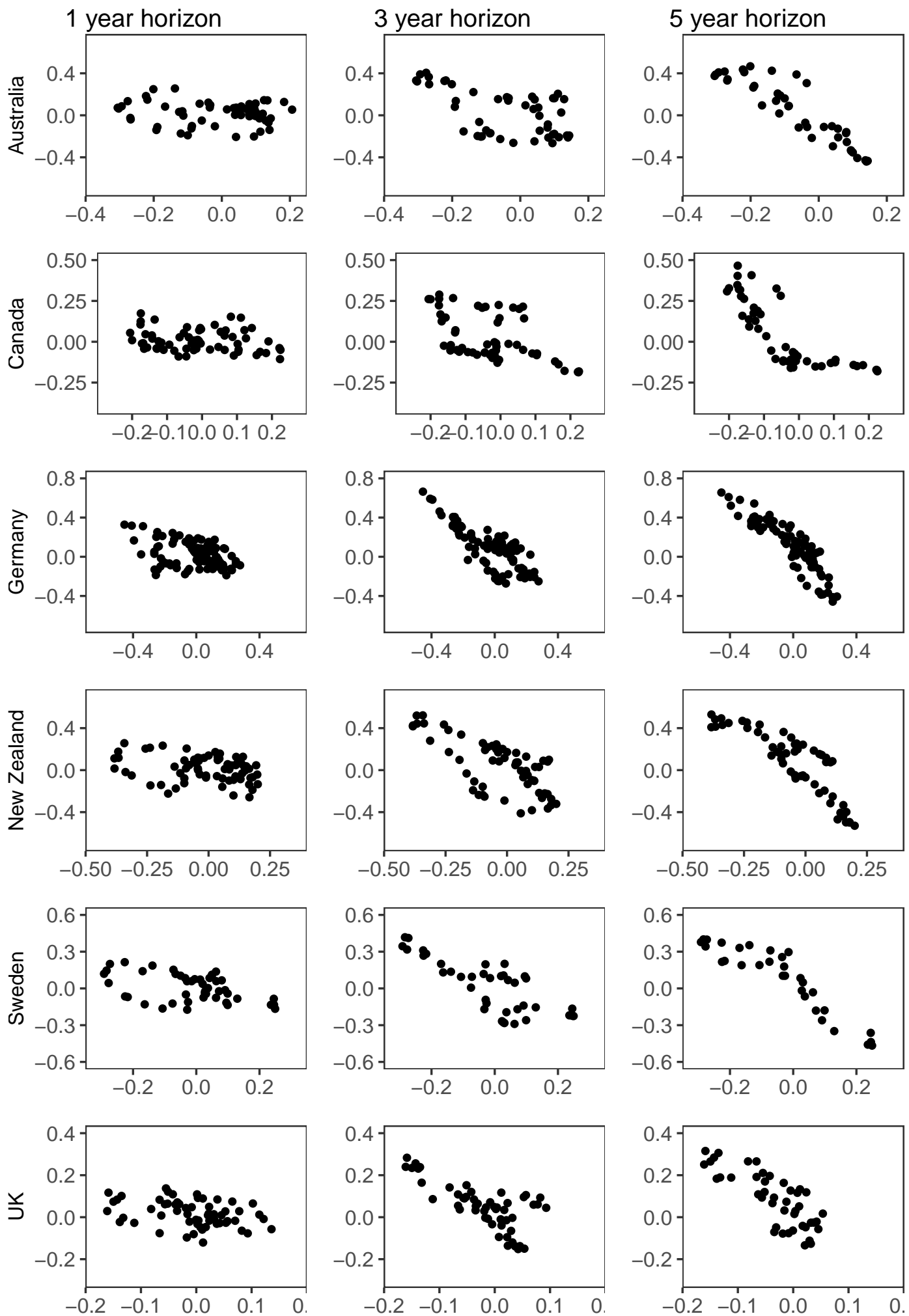

Note: Horizonal axis is the $\log$ of the $R E R$. Vertical axis is the future change in the $\log$ of the $N E R$ at the specified horizon. Sources: International Monetary Fund, International Financial Statistics; authors' calculations. 
Table 1: NER regression results

\begin{tabular}{lcccc} 
& \multicolumn{5}{c}{$\beta_{i, h}^{N E R}$} \\
& 1 & 3 & 5 & 7 \\
\hline & & & & \\
(a) Benchmark countries & & & & \\
\hline Australia & -0.10 & -0.84 & -1.95 & -1.99 \\
& $(0.17)$ & $(0.20)$ & $(0.08)$ & $(0.14)$ \\
Canada & -0.11 & -0.68 & -1.35 & -1.74 \\
& $(0.14)$ & $(0.17)$ & $(0.30)$ & $(0.30)$ \\
Germany & -0.27 & -0.97 & -1.34 & -1.58 \\
& $(0.12)$ & $(0.10)$ & $(0.16)$ & $(0.13)$ \\
New Zealand & -0.21 & -1.06 & -1.62 & -1.44 \\
\multirow{4}{*}{ Sweden } & $(0.13)$ & $(0.13)$ & $(0.25)$ & $(0.15)$ \\
& -0.36 & -1.12 & -1.57 & -1.31 \\
United Kingdom & $(0.13)$ & $(0.13)$ & $(0.15)$ & $(0.04)$ \\
& -0.26 & -1.09 & -1.68 & -1.08 \\
& $(0.10)$ & $(0.45)$ & $(0.15)$ & $(0.44)$ \\
(b) Managed exchange rates & & & & \\
\hline China & -0.10 & -0.32 & -0.40 & -0.30 \\
Hong Kong & $(0.04)$ & $(0.13)$ & $(0.21)$ & $(0.19)$ \\
& 0.04 & 0.04 & 0.03 & 0.02 \\
& $(0.04)$ & $(0.04)$ & $(0.04)$ & $(0.04)$
\end{tabular}

Sources: International Monetary Fund, International Financial Statistics; authors' calculations. 
Table 2: Relative price regression results

\begin{tabular}{lcccc} 
& \multicolumn{5}{c}{$\beta_{i, h}^{\pi}$} \\
& 1 & 3 & 5 & 7 \\
\hline & & & & \\
(a) Benchmark countries & & & & \\
\hline Australia & -0.04 & -0.10 & -0.06 & -0.03 \\
& $(0.01)$ & $(0.04)$ & $(0.04)$ & $(0.02)$ \\
Canada & -0.05 & -0.13 & -0.14 & -0.15 \\
& $(0.01)$ & $(0.01)$ & $(0.03)$ & $(0.04)$ \\
Germany & 0.02 & 0.08 & 0.14 & 0.14 \\
& $(0.01)$ & $(0.03)$ & $(0.06)$ & $(0.06)$ \\
New Zealand & -0.01 & -0.06 & -0.09 & -0.08 \\
& $(0.01)$ & $(0.02)$ & $(0.01)$ & $(0.02)$ \\
Sweden & -0.05 & -0.06 & 0.00 & -0.00 \\
& $(0.02)$ & $(0.02)$ & $(0.02)$ & $(0.02)$ \\
United Kingdom & -0.02 & -0.03 & -0.01 & -0.08 \\
& $(0.01)$ & $(0.04)$ & $(0.05)$ & $(0.05)$
\end{tabular}

(b) Managed exchange rates

\begin{tabular}{lcccc}
\hline China & -0.41 & -0.90 & -1.04 & -0.98 \\
& $(0.17)$ & $(0.18)$ & $(0.07)$ & $(0.01)$ \\
Hong Kong & -0.09 & -0.38 & -0.79 & -1.18 \\
& $(0.06)$ & $(0.14)$ & $(0.16)$ & $(0.15)$
\end{tabular}

(c) Euro area vis-a-vis Germany

\begin{tabular}{lcccc}
\hline France & -0.11 & -0.77 & -1.40 & -1.39 \\
& $(0.09)$ & $(0.27)$ & $(0.25)$ & $(0.22)$ \\
Italy & -0.19 & -0.54 & -0.77 & -0.82 \\
& $(0.05)$ & $(0.09)$ & $(0.11)$ & $(0.13)$ \\
Ireland & -0.27 & -0.80 & -1.12 & -1.45 \\
& $(0.09)$ & $(0.05)$ & $(0.05)$ & $(0.04)$ \\
Portugal & -0.24 & -0.68 & -0.89 & -1.05 \\
& $(0.05)$ & $(0.06)$ & $(0.05)$ & $(0.04)$ \\
Spain & -0.16 & -0.47 & -0.73 & -0.93 \\
& $(0.03)$ & $(0.08)$ & $(0.08)$ & $(0.06)$
\end{tabular}

Sources: International Monetary Fund, International Financial Statistics; authors' calculations. 
Table 3: NER regression results, other countries

$\beta_{i, h}^{N E R}: \quad$ Before inflation targeting

Horizon (in years)

\begin{tabular}{llll}
\hline 1 & 3 & 5 & 7 \\
\hline
\end{tabular}

$\begin{array}{ccccc}\text { Brazil } & 1.01 & 2.33 & 2.66 & 6.58 \\ & (1.08) & (3.17) & (2.53) & (1.80) \\ \text { Chile } & -0.15 & -0.77 & -1.45 & -2.16 \\ & (0.23) & (0.74) & (0.60) & (0.23) \\ \text { Colombia } & -0.15 & -0.72 & -1.29 & -1.66 \\ & (0.10) & (0.17) & (0.23) & (0.19) \\ \text { Israel } & 2.20 & 2.88 & 2.73 & 2.29 \\ & (0.90) & (1.29) & (1.01) & (1.30) \\ \text { Mexico } & 0.77 & 0.78 & 0.60 & 1.18 \\ & (0.37) & (0.55) & (0.60) & (0.77) \\ \text { Norway } & -0.17 & -0.65 & -0.86 & -0.94 \\ & (0.13) & (0.10) & (0.13) & (0.07) \\ \text { Peru } & 0.21 & 2.10 & 5.48 & 8.11 \\ & (0.41) & (1.23) & (1.23) & (0.95) \\ \text { Philippines } & -0.26 & -0.68 & -1.16 & -1.22 \\ & (0.22) & (0.10) & (0.17) & (0.13) \\ \text { S. Africa } & -0.40 & -0.94 & -0.96 & -1.12 \\ & (0.11) & (0.23) & (0.08) & (0.04) \\ \text { S. Korea } & -0.32 & -1.15 & -1.27 & -1.27 \\ & (0.14) & (0.16) & (0.12) & (0.23) \\ \text { Thailand } & -0.49 & -2.01 & -1.42 & -0.81 \\ & (0.13) & (0.84) & (0.82) & (0.43)\end{array}$

\begin{tabular}{cccc}
\multicolumn{5}{c}{ During inflation targeting } \\
Horizon & (in years) \\
\hline 1 & 3 & 5 & 7 \\
\hline & & & \\
-0.18 & -0.64 & -1.19 & -1.47 \\
$(0.12)$ & $(0.19)$ & $(0.13)$ & $(0.07)$ \\
-0.34 & -1.00 & -1.29 & -1.33 \\
$(0.14)$ & $(0.16)$ & $(0.13)$ & $(0.11)$ \\
-0.16 & -0.57 & -1.06 & -1.37 \\
$(0.13)$ & $(0.25)$ & $(0.19)$ & $(0.11)$ \\
-0.44 & -0.67 & -1.20 & -1.31 \\
$(0.13)$ & $(0.17)$ & $(0.27)$ & $(0.29)$ \\
-0.24 & -0.50 & -0.50 & -0.38 \\
$(0.15)$ & $(0.32)$ & $(0.45)$ & $(0.32)$ \\
-0.38 & -0.96 & -1.67 & -1.82 \\
$(0.14)$ & $(0.20)$ & $(0.28)$ & $(0.19)$ \\
-0.26 & -0.80 & -1.24 & -1.66 \\
$(0.11)$ & $(0.19)$ & $(0.14)$ & $(0.10)$ \\
-0.11 & -0.44 & -0.71 & -0.89 \\
$(0.09)$ & $(0.12)$ & $(0.10)$ & $(0.08)$ \\
-0.38 & -1.34 & -1.57 & -1.11 \\
$(0.10)$ & $(0.14)$ & $(0.22)$ & $(0.12)$ \\
-0.50 & -0.92 & -1.20 & -0.92 \\
$(0.19)$ & $(0.27)$ & $(0.12)$ & $(0.09)$ \\
-0.15 & -0.45 & -0.74 & -0.97 \\
$(0.07)$ & $(0.13)$ & $(0.11)$ & $(0.06)$
\end{tabular}

Sources: International Monetary Fund, International Financial Statistics; authors' calculations. 
Table 4: Relative price regression results, other countries

$\beta_{i, h}^{\pi}: \quad$ Before inflation targeting

Horizon (in years)

\begin{tabular}{lllll}
\hline 1 & 3 & 5 & 7 \\
\hline
\end{tabular}

\begin{tabular}{|c|c|c|c|c|c|c|c|c|}
\hline \multirow[t]{2}{*}{ Brazil } & -1.21 & -2.92 & -3.30 & -7.23 & -0.02 & 0.01 & 0.09 & 0.11 \\
\hline & $(1.10)$ & $(3.23)$ & $(2.53)$ & $(1.85)$ & $(0.02)$ & $(0.05)$ & $(0.03)$ & $(0.03)$ \\
\hline \multirow[t]{2}{*}{ Chile } & -0.13 & -0.12 & 0.14 & 0.69 & 0.06 & 0.17 & 0.17 & 0.12 \\
\hline & $(0.14)$ & $(0.47)$ & $(0.43)$ & $(0.20)$ & $(0.02)$ & $(0.04)$ & $(0.05)$ & $(0.04)$ \\
\hline \multirow[t]{2}{*}{ Colombia } & -0.12 & -0.22 & -0.12 & 0.02 & -0.03 & -0.04 & -0.04 & -0.07 \\
\hline & $(0.02)$ & $(0.05)$ & $(0.06)$ & $(0.12)$ & $(0.02)$ & $(0.05)$ & $(0.03)$ & $(0.03)$ \\
\hline \multirow[t]{2}{*}{ Israel } & -2.37 & -3.60 & -3.58 & -3.18 & 0.10 & 0.07 & 0.03 & -0.16 \\
\hline & $(0.77)$ & $(1.21)$ & $(0.96)$ & $(1.22)$ & $(0.04)$ & $(0.09)$ & $(0.15)$ & $(0.07)$ \\
\hline \multirow[t]{2}{*}{ Mexico } & -1.11 & -1.62 & -1.75 & -2.12 & -0.02 & 0.03 & -0.02 & 0.09 \\
\hline & $(0.24)$ & $(0.39)$ & $(0.53)$ & $(0.65)$ & $(0.02)$ & $(0.08)$ & $(0.10)$ & $(0.04)$ \\
\hline \multirow[t]{2}{*}{ Norway } & -0.09 & -0.34 & -0.44 & -0.43 & 0.00 & 0.10 & 0.23 & 0.23 \\
\hline & $(0.02)$ & $(0.04)$ & $(0.04)$ & $(0.04)$ & $(0.02)$ & $(0.03)$ & $(0.03)$ & $(0.02)$ \\
\hline \multirow[t]{2}{*}{ Peru } & -0.38 & -2.62 & -6.34 & -9.17 & 0.08 & 0.22 & 0.29 & 0.37 \\
\hline & $(0.42)$ & $(1.32)$ & (1.28) & $(0.98)$ & $(0.02)$ & $(0.04)$ & $(0.05)$ & $(0.06)$ \\
\hline \multirow[t]{2}{*}{ Philippines } & -0.10 & -0.12 & -0.49 & -0.51 & -0.01 & -0.08 & -0.15 & -0.22 \\
\hline & $(0.09)$ & $(0.09)$ & $(0.10)$ & $(0.32)$ & $(0.01)$ & $(0.03)$ & $(0.03)$ & $(0.02)$ \\
\hline \multirow[t]{2}{*}{ S. Africa } & -0.07 & -0.19 & -0.28 & -0.33 & -0.05 & 0.11 & 0.29 & 0.18 \\
\hline & $(0.08)$ & $(0.09)$ & $(0.18)$ & $(0.21)$ & $(0.03)$ & $(0.03)$ & $(0.03)$ & $(0.02)$ \\
\hline \multirow[t]{2}{*}{ S. Korea } & 0.09 & 0.22 & 0.18 & 0.11 & 0.00 & 0.02 & 0.09 & 0.08 \\
\hline & $(0.03)$ & $(0.04)$ & $(0.05)$ & $(0.08)$ & $(0.02)$ & $(0.05)$ & $(0.05)$ & $(0.02)$ \\
\hline \multirow[t]{2}{*}{ Thailand } & 0.04 & 0.09 & -0.21 & -0.52 & 0.01 & -0.02 & -0.07 & -0.09 \\
\hline & $(0.05)$ & $(0.26)$ & $(0.26)$ & $(0.15)$ & $(0.02)$ & $(0.04)$ & $(0.04)$ & $(0.05)$ \\
\hline
\end{tabular}

During inflation targeting

Horizon (in years)

\begin{tabular}{llll}
\hline 1 & 3 & 5 & 7 \\
\hline
\end{tabular}

Sources: International Monetary Fund, International Financial Statistics; authors' calculations. 
Table 5: Out-of-sample forecasting for the NER

Forecast horizon (in years)

\begin{tabular}{llllll}
\hline 1 & 2 & 3 & 4 & 5 & 6 \\
\hline
\end{tabular}

(a) RMSPE relative to random walk

\begin{tabular}{rcccccc}
\hline All countries & 1.08 & 1.03 & 0.93 & 0.76 & 0.62 & 0.50 \\
& & & & & & \\
Australia & 1.11 & 1.11 & 1.06 & 0.89 & 0.68 & 0.45 \\
Canada & 1.24 & 1.34 & 1.26 & 1.06 & 0.89 & 0.85 \\
Germany & 1.04 & 0.97 & 0.83 & 0.64 & 0.50 & 0.37 \\
New Zealand & 1.05 & 0.98 & 0.83 & 0.66 & 0.53 & 0.43 \\
Sweden & 1.07 & 0.98 & 0.82 & 0.63 & 0.50 & 0.31 \\
United Kingdom & 1.03 & 0.96 & 0.86 & 0.77 & 0.72 & 0.72 \\
& & & & & & \\
(b) Bootstrap p-values (stationary & $R E R)$ & & \\
\hline All countries & 0.82 & 0.40 & 0.05 & 0.00 & 0.00 & 0.00 \\
& & & & & & \\
Australia & 0.90 & 0.77 & 0.59 & 0.12 & 0.02 & 0.00 \\
Canada & 0.92 & 0.88 & 0.75 & 0.43 & 0.11 & 0.09 \\
Germany & 0.58 & 0.15 & 0.03 & 0.00 & 0.00 & 0.00 \\
New Zealand & 0.72 & 0.21 & 0.02 & 0.00 & 0.00 & 0.00 \\
Sweden & 0.82 & 0.26 & 0.06 & 0.01 & 0.01 & 0.00 \\
United Kingdom & 0.40 & 0.15 & 0.07 & 0.03 & 0.02 & 0.03 \\
& & & & & & \\
(c) Bootstrap p-values (non-stationary & $R E R)$ & \\
\hline All countries & 0.33 & 0.11 & 0.03 & 0.01 & 0.00 & 0.00 \\
& & & & & & \\
Australia & 0.60 & 0.46 & 0.37 & 0.21 & 0.08 & 0.02 \\
Canada & 0.70 & 0.64 & 0.49 & 0.31 & 0.19 & 0.16 \\
Germany & 0.31 & 0.18 & 0.10 & 0.03 & 0.01 & 0.00 \\
New Zealand & 0.39 & 0.20 & 0.08 & 0.02 & 0.01 & 0.00 \\
Sweden & 0.65 & 0.36 & 0.16 & 0.06 & 0.03 & 0.01 \\
United Kingdom & 0.36 & 0.22 & 0.14 & 0.10 & 0.09 & 0.10
\end{tabular}

Note: Sources: International Monetary Fund, International Financial Statistics; authors' calculations. 
Figure 2: Response to endowment shock
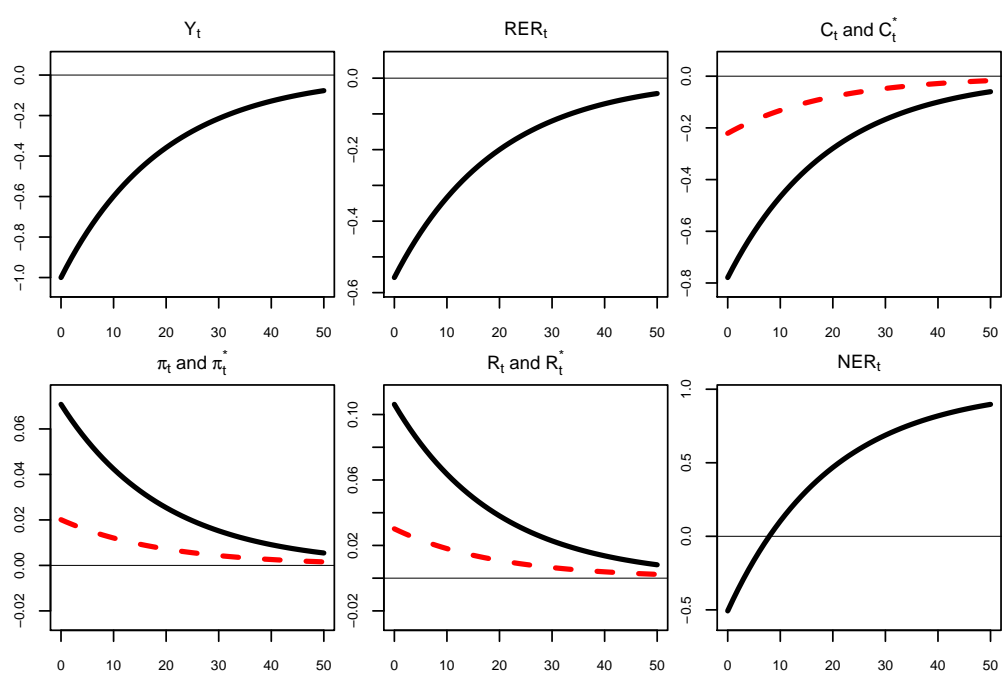

Note: The vertical axis is expressed in percent. The horizontal axis shows quarters after the shock. Red-dashed lines indicate the variables for the foreign country.

Table 6: Posterior distribution: non-shock parameters

Prior

Posterior

Shape (mean, std. dev.) mode st. dev. [5\%, 95\%]

U.S.

$\begin{array}{llllll}\gamma_{1} & \text { Taylor rule persistence } & \text { Beta }(0.75,0.05) & 0.90 & 0.01 & {[0.87,0.92]}\end{array}$

$\theta_{\pi, 1}-1 \quad$ Taylor rule inflation coef. $\quad$ Inv. Gamma $(0.7,0.15) \quad 0.60 \quad 0.12 \quad[0.47,0.92]$

$\begin{array}{llllll}\theta_{G D P, 1} & \text { Taylor rule GDP coef. } & \text { Beta }(0.10,0.05) & 0.10 & 0.03 & {[0.07,0.17]}\end{array}$

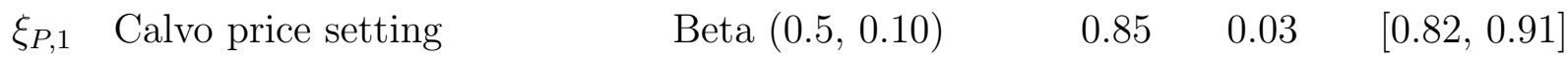

$\begin{array}{lllll}\xi_{W, 1} \quad \text { Calvo wage setting } & \text { Beta }(0.5,0.10) & 0.65 & 0.06 & {[0.57,0.78]}\end{array}$

$S_{1}^{\prime \prime}(1) \quad$ Investment adj. costs $\quad$ Normal $(4.00,1.50) \quad 5.33 \quad 1.06 \quad[3.99,7.45]$

$\frac{a_{1}^{\prime \prime}(1) / a_{1}^{\prime}(1)}{a_{1}^{\prime \prime}(1) / a_{1}^{\prime}(1)+1} \quad$ Utilization adj. costs $\quad$ Beta $(0.50,0.15) \quad 0.63 \quad 0.11 \quad[0.43,0.80]$

$\begin{array}{llllll}\varphi_{1} & \text { Net export adj. costs } & \text { Normal }(10,2) & 12.31 & 1.79 & {[9.43,15.28]}\end{array}$

Germany

$\begin{array}{llllll}\gamma_{2} & \text { Taylor rule persistence } & \text { Beta }(0.75,0.05) & 0.90 & 0.01 & {[0.88,0.92]}\end{array}$

$\theta_{\pi, 2}-1 \quad$ Taylor rule inflation coef. $\quad$ Inv. Gamma $(0.7,0.15) \quad 0.55 \quad 0.10 \quad[0.43,0.76]$

$\begin{array}{llllll}\theta_{G D P, 2} & \text { Taylor rule GDP coef. } & \text { Beta }(0.10,0.05) & 0.09 & 0.03 & {[0.05,0.17]}\end{array}$

$\begin{array}{llllll}\xi_{P, 2} & \text { Calvo price setting } & \text { Beta }(0.5,0.10) & 0.51 & 0.08 & {[0.45,0.71]}\end{array}$

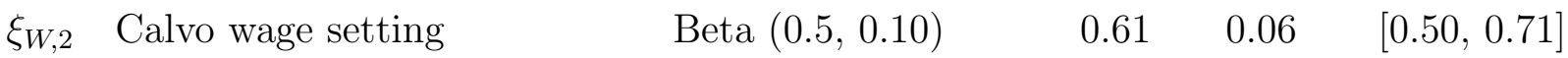

$\begin{array}{lllll}S_{2}^{\prime \prime}(1) & \text { Investment adj. costs } \quad \text { Normal }(4.00,1.50) & 5.28 & 1.08 & {[3.83,7.38]}\end{array}$

$\frac{a_{2}^{\prime \prime}(1) / a_{2}^{\prime}(1)}{a_{2}^{\prime \prime}(1) / a_{2}^{\prime}(1)+1} \quad$ Utilization adj. costs $\quad$ Beta $(0.50,0.15) \quad 0.68 \quad 0.12 \quad[0.46,0.85]$

$\varphi_{2}$ Net export adj. costs $\quad$ Normal $(10,2) \quad 9.41 \quad 2.04 \quad[5.99,12.65]$

Note: In our Bayesian estimation, we simulate two MCMC chains of length 200,000. We discard the first 100,000 draws from each chain, and we keep every 5th draw after the first 100,000 draws. 
Table 7: Posterior distribution: shock process persistence

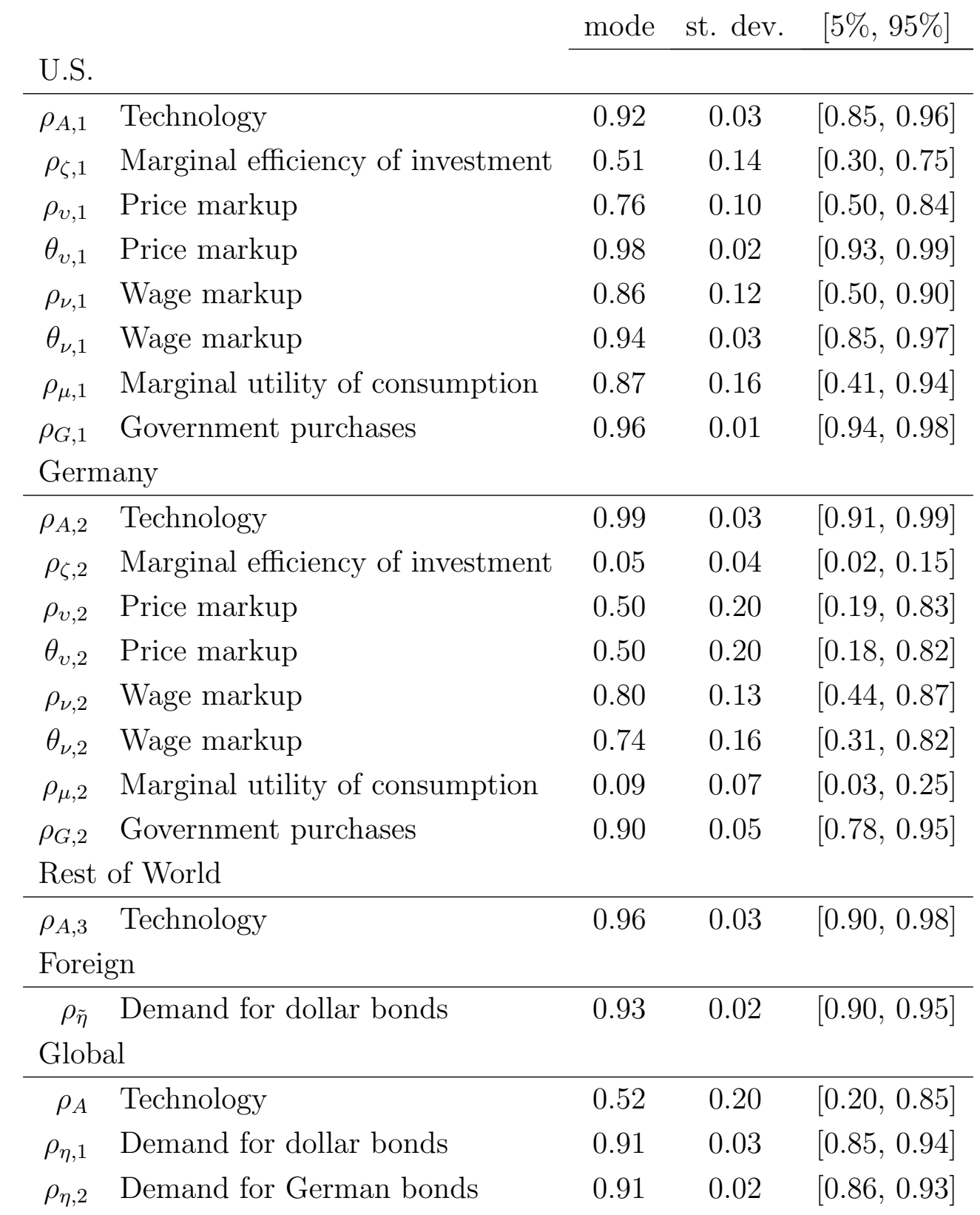

Note: We use a Beta prior with mean 0.5 and standard deviation 0.2 for all parameters shown in this table. 
Table 8: Posterior distribution: shock process volatility

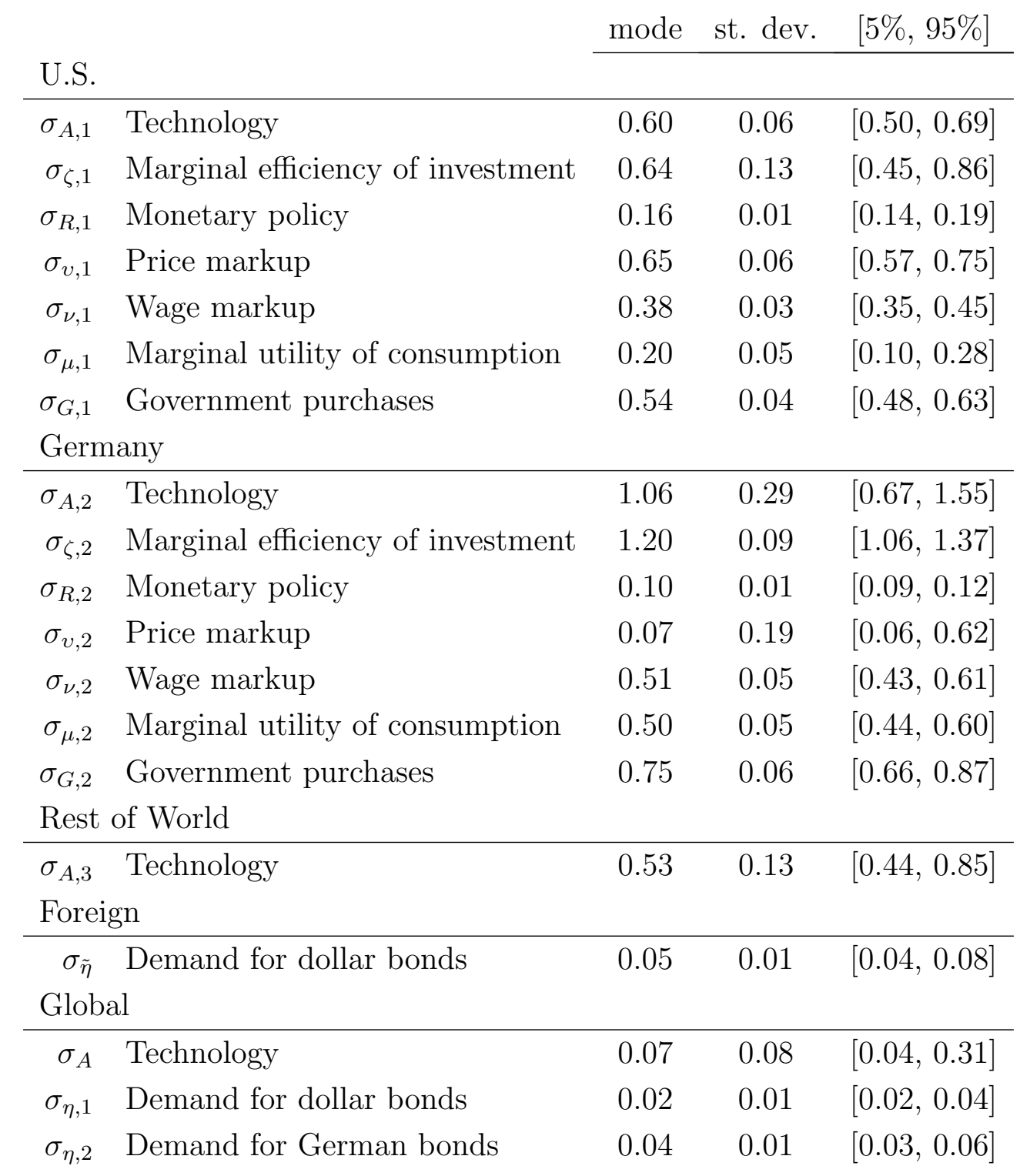

Note: We use an Inverse Gamma prior with mean 0.2 and standard deviation 1 for all parameters shown in this table. 
Table 9: Variance decomposition of US/German RER

\begin{tabular}{rlccc} 
& & \multicolumn{3}{c}{$\begin{array}{c}\text { Frequency } \\
\text { (in quarters) }\end{array}$} \\
\cline { 3 - 5 } & & $1-8$ & $8-32$ & $32-100$ \\
\hline$\tilde{\eta}_{t}$ & Foreign demand for dollar bonds & 71 & 73 & 86 \\
$\eta_{2, t}$ & Demand for German bonds & 12 & 8 & 3 \\
$\eta_{1, t}$ & Global demand for dollar bonds & 6 & 5 & 2 \\
$R_{1, t}$ & U.S. Monetary policy & 4 & 3 & 1 \\
$A_{2, t}$ & German technology & 3 & 5 & 4 \\
$R_{2, t}$ & German Monetary policy & 2 & 1 & 0 \\
$v_{1, t}$ & U.S. price markup & 1 & 2 & 0 \\
$\nu_{2, t}$ & German wage markup & 0 & 2 & 1
\end{tabular}

Note: Statistics are computed using parameter values from the posterior mode. Shocks are excluded from the table if they account for less than 2 percent of the variance at each frequency.

Table 10: Variance decomposition of US GDP

\begin{tabular}{rlccc} 
& & \multicolumn{3}{c}{$\begin{array}{c}\text { Frequency } \\
\text { (in quarters) }\end{array}$} \\
\cline { 3 - 5 } U.S. & & $1-8$ & $8-32$ & $32-100$ \\
\hline$\eta_{1, t}$ & Global demand for dollar bonds & 17 & 23 & 21 \\
$\zeta_{1, t}$ & U.S. marginal efficiency of investment & 18 & 16 & 10 \\
$R_{1, t}$ & U.S. monetary policy & 12 & 16 & 13 \\
$v_{1, t}$ & U.S. price markup & 1 & 16 & 16 \\
$G_{1, t}$ & U.S. government purchases & 30 & 9 & 6 \\
$\tilde{\eta}_{t}$ & Rest-of-World demand for dollar bonds & 19 & 7 & 5 \\
$A_{1, t}$ & U.S. technology & 1 & 7 & 18 \\
$\mu_{1, t}$ & U.S. marginal utility of consumption & 0 & 4 & 2 \\
$\nu_{1, t}$ & U.S. wage markup & 2 & 2 & 9
\end{tabular}

Note: Statistics are computed using parameter values from the posterior mode. Shocks are excluded from the table if they account for less than 2 percent of the variance at each frequency. 
Table 11: Variance decomposition of German GDP

\begin{tabular}{clccc} 
& & \multicolumn{3}{c}{$\begin{array}{c}\text { Frequency } \\
\text { (in quarters) }\end{array}$} \\
\cline { 3 - 6 } U.S. & $1-8$ & $8-32$ & $32-100$ \\
\hline$A_{2, t}$ & German technology & 5 & 36 & 61 \\
$\eta_{2, t}$ & Global demand for German bonds & 25 & 26 & 16 \\
$\nu_{2, t}$ & German wage markup & 1 & 12 & 13 \\
$G_{2, t}$ & German government purchases & 32 & 11 & 4 \\
$\mu_{2, t}$ & German marginal utility of consumption & 20 & 6 & 1 \\
$\zeta_{2, t}$ & German marginal efficiency of investment & 11 & 4 & 2 \\
$R_{2, t}$ & German monetary policy & 4 & 4 & 2
\end{tabular}

Note: Statistics are computed using parameter values from the posterior mode. Shocks are excluded from the table if they account for less than 2 percent of the variance at each frequency.

Table 12: Shocks driving NER regression coefficients in estimated DSGE model

\begin{tabular}{rlcccc} 
& & \multicolumn{4}{c}{ Horizon } \\
& & \multicolumn{4}{c}{ (in years) } \\
\cline { 3 - 6 } & & 3 & 5 & 7 \\
\hline$\tilde{\eta}_{t}$ & Foreign demand for dollar bonds & 70 & 74 & 74 & 73 \\
$A_{2, t}$ & German technology & 9 & 10 & 12 & 14 \\
$\eta_{2, t}$ & Global demand for German bonds & 6 & 4 & 3 & 3 \\
$\eta_{1, t}$ & Global demand for dollar bonds & 4 & 2 & 2 & 2 \\
$\nu_{2, t}$ & German wage markup & 3 & 3 & 2 & 2 \\
$R_{1, t}$ & U.S. monetary policy & 3 & 2 & 2 & 1
\end{tabular}

Note: The table show the percent of the correlation between the $R E R$ and future changes in the $N E R$ accounted for by each shock at different horizons. Statistics are computed using parameter values from the posterior mode. 
Table 13: Regression coefficients in estimated DSGE model

\begin{tabular}{crrrr} 
& \multicolumn{5}{c}{ Horizon (in years) } \\
\hline (a) NER regression coefficient, $\beta_{i, h}^{N E R}$ & 1 & 3 & 5 & 7 \\
\hline Asymptotic value & & & & \\
Small-sample mean & -0.28 & -0.62 & -0.80 & -0.91 \\
Small-sample st. dev. & -0.40 & -0.81 & -1.00 & -1.08 \\
& 0.17 & 0.30 & 0.38 & 0.44
\end{tabular}

(a) Relative-price regression coefficient, $\beta_{i, h}^{\pi}$

$\begin{array}{crrrr}\text { Asymptotic value } & -0.02 & -0.02 & -0.01 & -0.00 \\ \text { Small-sample mean } & -0.04 & -0.05 & -0.05 & -0.04 \\ \text { Small-sample st. dev. } & 0.06 & 0.17 & 0.26 & 0.32\end{array}$

Note: Statistics are computed using parameter values from the posterior mode of our benchmark model. The row labeled asymptotic value refers to regressions run on a time series of length 1,000,000 and the row labeled small-sample mean refers to the mean of the estimates from 10,000 regressions run on simulated time series, each of length 100. The row labeled small-sample st. dev. refers to the standard deviation of the estimates across the 10,000 regressions.

Figure 3: Response to foreign demand for dollar-denominated bonds
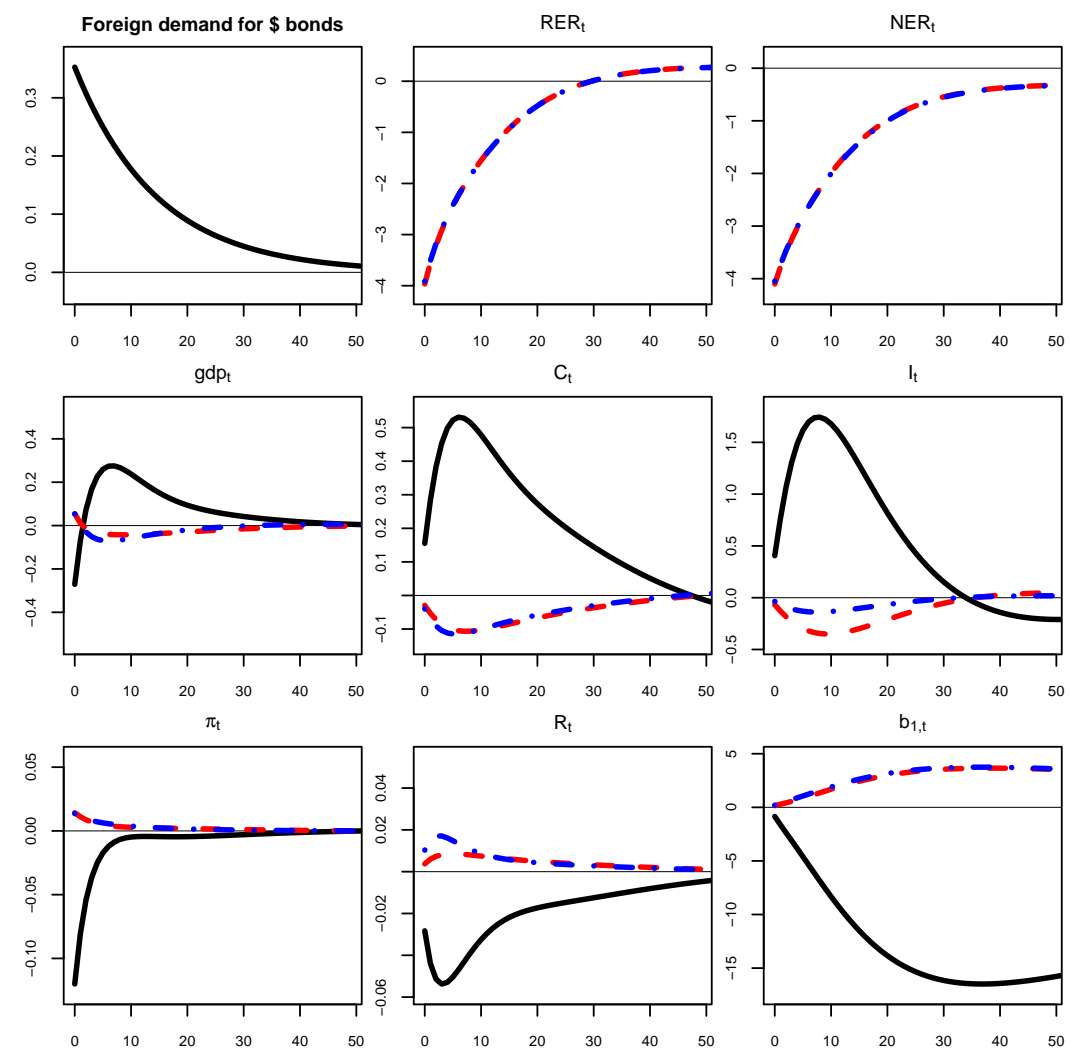

Note: The vertical axis is expressed in percent. The horizontal axis shows quarters after the shock. Black lines indicate the variables for the U.S.. Red-dashed lines indicate the variables for Germany. Blue dashed-dotted lines indicate the variables for the rest of the World. 
Table 14: Regression coefficients in estimated DSGE model, NER target

\begin{tabular}{crrrr} 
& \multicolumn{5}{c}{ Horizon (in years) } \\
\hline (a) NER regression coefficient, $\beta_{i, h}^{N E R}$ & 1 & 3 & 5 & 7 \\
\hline Asymptotic value & & & & \\
Small-sample mean & -0.13 & -0.19 & -0.19 & -0.19 \\
Small-sample st. dev. & -0.23 & -0.32 & -0.31 & -0.30 \\
& 0.10 & 0.13 & 0.13 & 0.15
\end{tabular}

(a) Relative-price regression coefficient, $\beta_{i, h}^{\pi}$

$\begin{array}{crrrr}\text { Asymptotic value } & -0.03 & -0.28 & -0.49 & -0.62 \\ \text { Small-sample mean } & -0.05 & -0.44 & -0.72 & -0.84 \\ \text { Small-sample st. dev. } & 0.06 & 0.20 & 0.27 & 0.33\end{array}$

Note: Statistics are computed using parameter values from the posterior mode of our benchmark model. The row labeled asymptotic value refers to regressions run on a time series of length 1,000,000 and the row labeled small-sample mean refers to the mean of the estimates from 10,000 regressions run on simulated time series, each of length 100. The row labeled small-sample st. dev. refers to the standard deviation of the estimates across the 10,000 regressions.

Table 15: Regression coefficients in estimated DSGE model, capital controls

\begin{tabular}{crrrr} 
& \multicolumn{5}{c}{ Horizon (in years) } \\
\hline (a) NER regression coefficient, $\beta_{i, h}^{N E R}$ & 1 & 3 & 5 & 7 \\
\hline Asymptotic value & & & & \\
Small-sample mean & -0.30 & -0.67 & -0.85 & -0.96 \\
Small-sample st. dev. & -0.42 & -0.85 & -1.02 & -1.09 \\
& 0.17 & 0.30 & 0.37 & 0.43
\end{tabular}

(a) Relative-price regression coefficient, $\beta_{i, h}^{\pi}$

$\begin{array}{crrrr}\text { Asymptotic value } & -0.02 & -0.00 & 0.02 & 0.04 \\ \text { Small-sample mean } & -0.04 & -0.04 & -0.03 & -0.02 \\ \text { Small-sample st. dev. } & 0.07 & 0.18 & 0.26 & 0.32\end{array}$

Note: Statistics are computed using parameter values from the posterior mode of our benchmark model. The row labeled asymptotic value refers to regressions run on a time series of length 1,000,000 and the row labeled small-sample mean refers to the mean of the estimates from 10,000 regressions run on simulated time series, each of length 100. The row labeled small-sample st. dev. refers to the standard deviation of the estimates across the 10,000 regressions. 